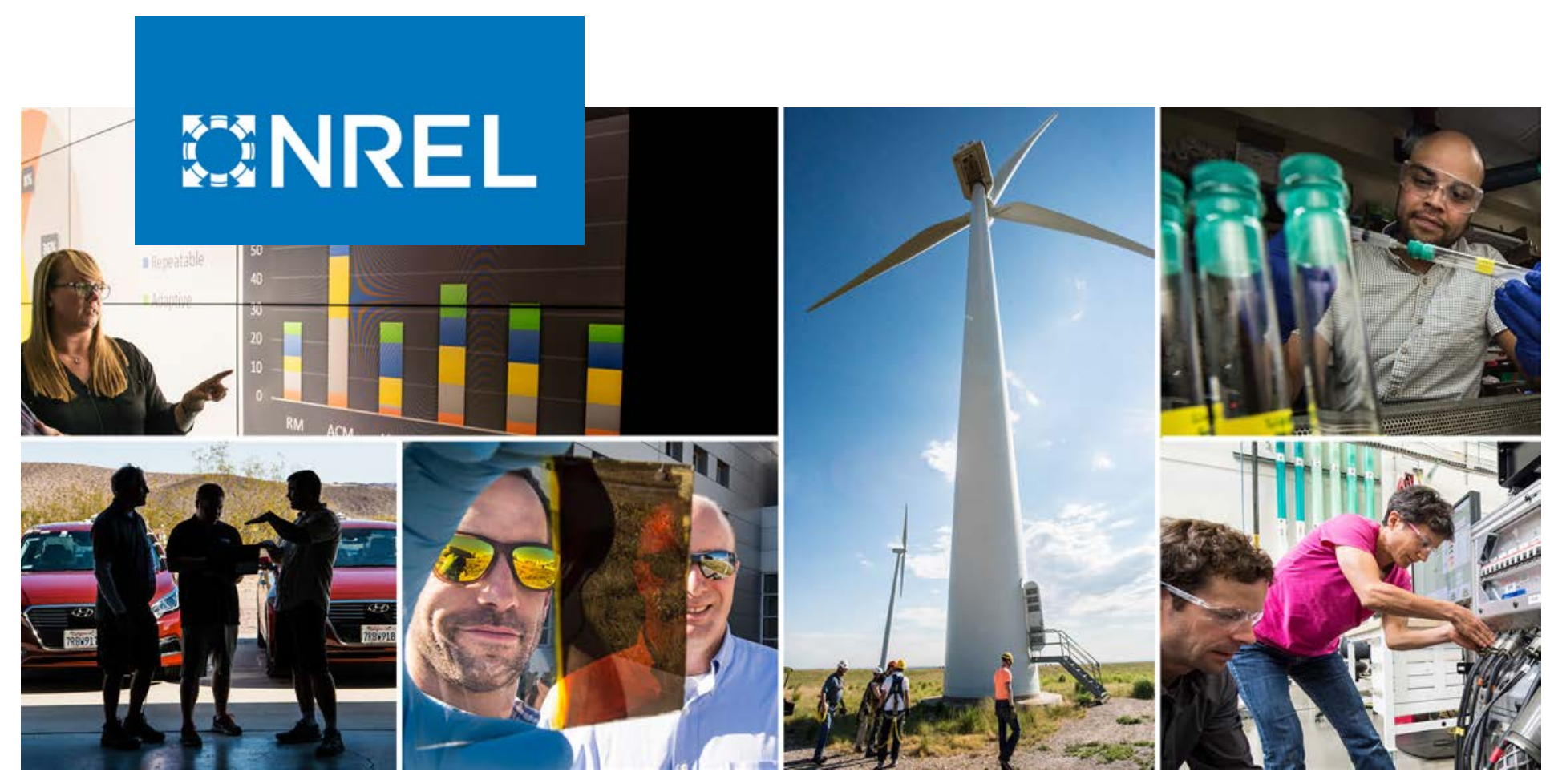

\title{
Financial Analysis of Battery Electric Transit Buses
}

Caley Johnson, Erin Nobler, Leslie Eudy, and Matthew Jeffers

National Renewable Energy Laboratory

NREL is a national laboratory of the U.S. Department of Energy

Office of Energy Efficiency \& Renewable Energy

Operated by the Alliance for Sustainable Energy, LLC

This report is available at no cost from the National Renewable Energy Laboratory (NREL) at www.nrel.gov/publications.
Technical Report

NREL/TP-5400-74832

June 2020 


\title{
GNREL
}

\section{Financial Analysis of Battery Electric Transit Buses}

\author{
Caley Johnson, Erin Nobler, Leslie Eudy, and Matthew Jeffers
}

National Renewable Energy Laboratory

\section{Suggested Citation}

Johnson, Caley, Erin Nobler, Leslie Eudy, and Matthew Jeffers. 2020. Financial Analysis of Battery Electric Transit Buses. Golden, CO: National Renewable Energy Laboratory.

NREL/TP-5400-74832. https://www.nrel.gov/docs/fy20osti/74832.pdf

NREL is a national laboratory of the U.S. Department of Energy Office of Energy Efficiency \& Renewable Energy Operated by the Alliance for Sustainable Energy, LLC

This report is available at no cost from the National Renewable Energy Laboratory (NREL) at www.nrel.gov/publications.

Contract No. DE-AC36-08GO28308
Technical Report NREL/TP-5400-74832 June 2020

National Renewable Energy Laboratory 15013 Denver West Parkway Golden, CO 80401 303-275-3000 • www.nrel.gov 


\section{NOTICE}

This work was authored by the National Renewable Energy Laboratory, operated by Alliance for Sustainable Energy, LLC, for the U.S. Department of Energy (DOE) under Contract No. DE-AC36-08GO28308. Funding provided by the U.S. Department of Energy Office of Energy Efficiency and Renewable Energy Vehicle Technologies Office. The views expressed herein do not necessarily represent the views of the DOE or the U.S. Government.

This report is available at no cost from the National Renewable Energy Laboratory (NREL) at www.nrel.gov/publications.

U.S. Department of Energy (DOE) reports produced after 1991 and a growing number of pre-1991 documents are available free via www.OSTI.gov.

Cover Photos by Dennis Schroeder: (clockwise, left to right) NREL 51934, NREL 45897, NREL 42160, NREL 45891, NREL 48097, NREL 46526.

NREL prints on paper that contains recycled content. 


\section{Acknowledgments}

The authors would like to thank the U.S. Department of Energy's Vehicle Technologies Office, Technology Integration Program for funding this project and providing connections with numerous transit agencies that led to key data and insight. We would like to thank the transit agencies that generously shared their electric load data, operational data, and technological insight. This project would not have been possible without data from the Transportation Cooperative Research Committee's 130 report and the shared vision from Meredith Linscott and Erik Bigelow. Likewise, we would like to thank our colleague at the National Renewable Energy Laboratory (NREL), Josh Eichman, who's field work with electric bus fleets proved invaluable. Other NREL colleagues, Daniel Zimny-Schmitt, Joyce McLaren, and Emma Elgqvist, helped us navigate the Utility Rate Database and better address the complex relationship between electric utility and bus fleet. Lisa Jerram of the American Public Transit Association and Andy Eiden of Portland General Electric shared perspectives that greatly benefited this study. Despite the large amount of help that we have received when writing this report, any potential errors are the fault of the authors. 


\section{List of Acronyms}

AFDC

AFLEET

APTA

BEB

BLS

CARB

CNG

DCA

EIA

EV

FTA

HVIP

$\mathrm{kW}$

$\mathrm{kWh}$

MTA

NPV

NREL

O\&M

PTI

ROI

RPM

RRR

URDB

TCRP

TOU

VICE

VICE-BEB

VMT
Alternative Fuels Data Center

Alternative Fuel Life-Cycle Environmental and Economic Transportation tool

American Public Transit Association

battery electric bus

Bureau of Labor Statistics

California Air Resources Board

compressed natural gas

discounted cashflow analysis

Energy Information Agency

electric vehicle

Federal Transit Administration

Hybrid and Zero-Emission Truck and Bus Voucher Incentive Program

kilowatt

kilowatt-hour

Metropolitan Transit Authority

net present value

National Renewable Energy Laboratory

operations and maintenance

Pennsylvania Transportation Institute

return on investment

revolutions per minute

required rate of return

Utility Rate Database

Transit Cooperative Research Program

Time of use

Vehicle and Infrastructure Cash-Flow Evaluation model

Vehicle and Infrastructure Cash-Flow Evaluation for battery electric buses vehicle miles traveled 


\section{Executive Summary}

Transit buses are well positioned to be the next heavy-duty vehicle market segment to significantly electrify. However, most fleet managers will only purchase battery electric buses (BEBs) if they are cost-effective when compared to traditional diesel buses over their lifetime. In this report, this comparison is done through the Vehicle and Infrastructure Cash-Flow Evaluation for BEB (VICE-BEB) model. This model determines the net present value (NPV) and the payback period for investment in BEBs and charging infrastructure.

Numerous economic analyses have been done for specific fleets, but this analysis strives to help all transit bus fleets determine if BEBs would be cost-effective. It does this by establishing a baseline fleet with typical or average values for the parameters of interest and then addressing variations to these parameters in a simplified way that allows specific fleets to place themselves on a spectrum based on key parameters. The baseline fleet was determined through an extensive literature search and fleet survey. The baseline scenario invested in four BEBs and four depot chargers, received a grant of $\$ 1,500,000$ (or $\$ 375,000$ per bus with charger), and saw an NPV of $\$ 785,000$ over the 12-year bus life.

When determining if BEB investment would be cost-effective (meaning lower total cost of ownership than diesel bus), fleet managers and grant administrators need to know which fleet parameters to prioritize. The most important parameters are the ones that are highly influential to NPV and highly volatile. The relative influence of parameters was determined by independently swinging 33 key VICE-BEB inputs $\pm 50 \%$ and recording the corresponding swing in project NPV. The volatility of each parameter was determined by dividing the range of inputs found in a literature search by the baseline value. The most influential and volatile project parameters are represented in Table ES-1.

Table ES-1. Most Influential and Volatile Project Parameters

\begin{tabular}{|c|c|c|}
\hline Parameter & $\begin{array}{c}\text { Influence } \\
\text { (NPV Swing) }\end{array}$ & Volatility Rating \\
\hline Purchase price of BEB & $\$ 3,200,968$ & Medium \\
\hline Purchase price of foregone diesel bus & $\$ 1,731,602$ & Low \\
\hline Grant amount & $\$ 1,500,000$ & Medium \\
\hline Diesel vehicle maintenance & $\$ 1,129,599$ & Medium \\
\hline Annual vehicle miles traveled (VMT) & $\$ 1,033,894$ & Medium \\
\hline Number of BEBs obtained (depot)a & $\$ 771,923$ & High \\
\hline BEB vehicle maintenance costs & $\$ 698,440$ & High \\
\hline Charger price (fast) ${ }^{a}$ & $\$ 495,636$ & High \\
\hline Number of BEBs obtained (fast) ${ }^{a}$ & $\$ 429,500$ & High \\
\hline Electricity demand charges (fast) ${ }^{a}$ & $\$ 49,282$ & High \\
\hline
\end{tabular}

${ }^{a}$ Parameters with parentheses behind them apply specifically to fast- or depot-charge projects.

Many of the parameters vary based upon temporal and geographical factors. Knowing the trends in variance can help a fleet determine beforehand if a BEB investment is likely to be costeffective for them. There are also a number of choices a fleet can make in order to make these parameters more favorable. Choosing between a fast and depot charger is implicated in many of these parameters, and charger power, electricity demand charges, and facility electric load patterns need to be considered when making this decision. BEB range is an intermediary factor 
that is impacted by important parameters (e.g., battery size, efficiency, duty cycle, temperature) and impacts important parameters (e.g., number of chargers and BEBs).

This report serves as a first screen to determine which fleets may be the most suitable for BEB investment. Next steps could include fleet-specific modeling with VICE-BEB; route profiling to help determine the real-world BEB efficiency, range, and equipment requirements; and discussions with the electric utility to determine if their rate structure and contract can be conducive to cost effective BEB projects. 


\section{Table of Contents}

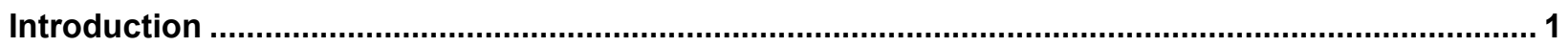

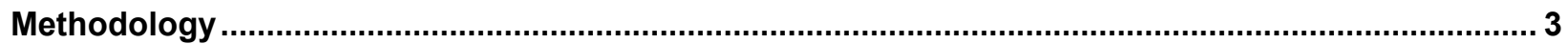

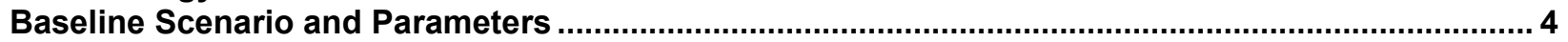

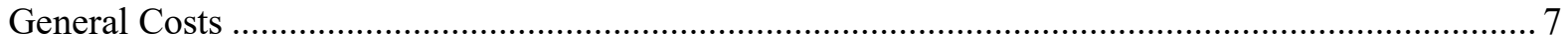

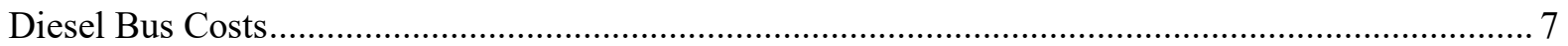

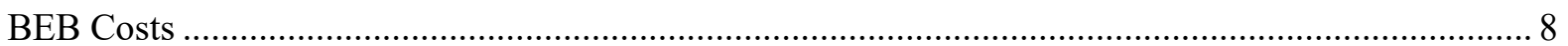

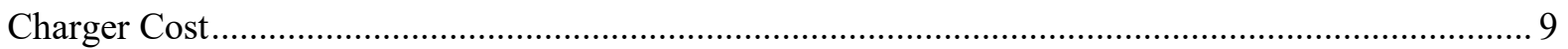

Electricity Demand Charges...................................................................................... 10

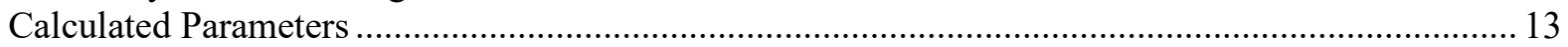

NPV and Payback of Baseline Scenario . ................................................................................... 13

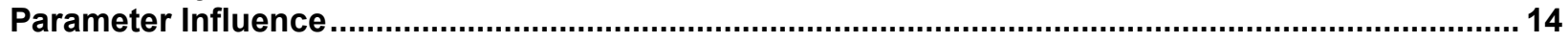

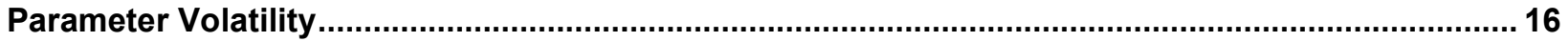

Key Parameters When Considering BEB Investment .................................................................. 18

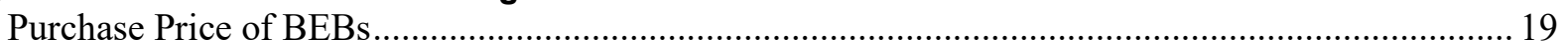

Purchase Price of the Foregone Diesel Bus........................................................................... 20

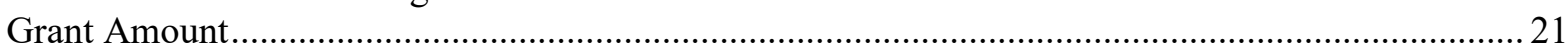

Maintenance Costs of Foregone Diesel Buses .................................................................. 22

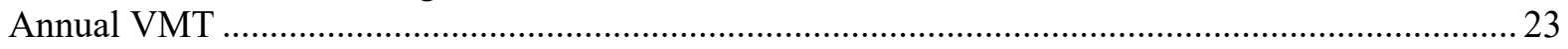

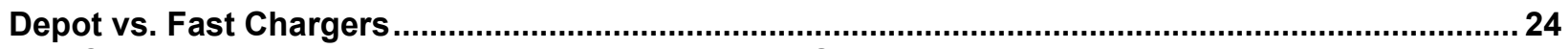

Top Considerations Related to Electric Utility Rate Structure and Load.....................................27

BEB Range ................................................................................................................................... 29

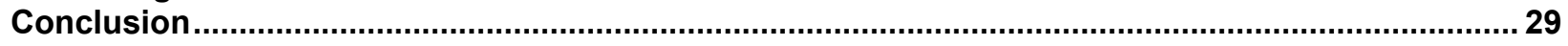

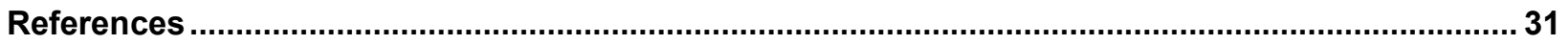

Appendix: Calculated Parameters................................................................................................. 36 


\section{List of Figures}

Figure 1. Hourly and monthly electrical load profiles for a diesel bus facility with no BEBs .................. 11

Figure 2. Cumulative discounted cashflow of depot-charge BEB project by year ................................... 14

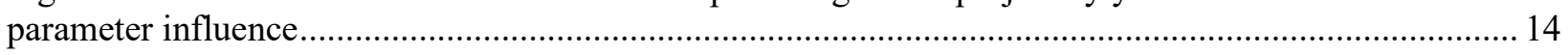

Figure 3. The effect of BEB purchase price on NPV under the fast- and depot-charge scenarios ............. 19

Figure 4. The effect of the foregone diesel bus price on BEB investment ............................................ 20

Figure 5. The effect that grant amount has on NPV under the fast- and depot-charge scenarios............... 22

Figure 6. The effect of the maintenance costs of foregone diesel buses on NPV of BEB investment ....... 23

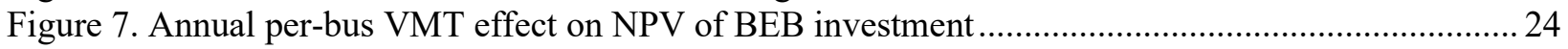

Figure 8. Depot vs. fast charger lifetime costs............................................................................... 25

Figure 9. Lifetime costs of chargers with varying demand charges, load delta, and equipment costs ....... 26

\section{List of Tables}

Table ES-1. Most Influential and Volatile Project Parameters .............................................................. v

Table 1. Heavy-Duty Vehicle Fleet Suitability for Electrification ........................................................ 1

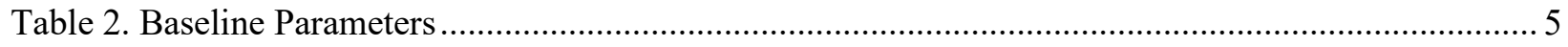

Table 3. The Swing in NPV Resulting from a $\pm 50 \%$ Swing in Each Parameter ..................................... 15

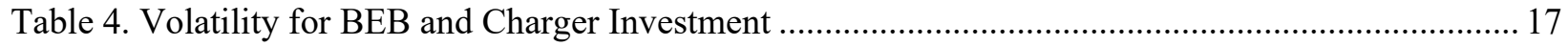

Table 5. Most Influential and Volatile Project Parameters ..................................................................... 18

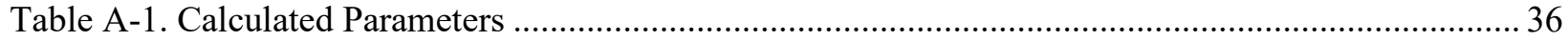




\section{Introduction}

Electric mobility is being pursued at the national, state, city, corporate, and organizational level in the United States (ICCT 2019, AFDC 2019). One strategy to expand the markets and infrastructure supporting these vehicles is to implement them in organized fleets (10 CFR Part 490). Fleet managers are more likely to be persuaded by life cycle financial analyses than individual owners because they value future cost savings more than individual owners (Hardman et al. 2017, Yang et al 2016, IEA 2017). Therefore, financial analyses are a key way to demonstrate future savings and enable fleet managers to determine the payback despite higher upfront costs than the incumbent vehicles.

This financial analysis focuses on transit buses because they are positioned to benefit from electrification sooner and to a greater degree than most other heavy-duty vehicles. As shown in Table 1 and listed in the text below, transit buses are particularly suitable for electrification for six major reasons.

Table 1. Heavy-Duty Vehicle Fleet Suitability for Electrification

\begin{tabular}{|c|c|c|c|c|c|c|}
\hline $\begin{array}{l}\text { Vehicle fleet } \\
\text { type }\end{array}$ & $\begin{array}{l}\text { Electric } \\
\text { vehicle } \\
\text { availability }\end{array}$ & $\begin{array}{l}\text { Compatibility of } \\
\text { routes and } \\
\text { charging needs }\end{array}$ & $\begin{array}{l}\text { f High } \\
\text { kinetic } \\
\text { intensity }\end{array}$ & $\begin{array}{l}\text { Idle } \\
\text { reduction } \\
\text { opportunity }\end{array}$ & $\begin{array}{l}\text { Valuation } \\
\text { of ancillary } \\
\text { benefits }\end{array}$ & $\begin{array}{l}\text { Quantity of } \\
\text { fuel } \\
\text { consumed }\end{array}$ \\
\hline \multicolumn{7}{|l|}{ Transit bus } \\
\hline \multicolumn{7}{|l|}{$\begin{array}{l}\text { Airport ground } \\
\text { support } \\
\text { equipment }\end{array}$} \\
\hline \multicolumn{7}{|l|}{ School bus } \\
\hline \multicolumn{7}{|l|}{ Shuttle bus } \\
\hline \multicolumn{7}{|c|}{ Campus/resort } \\
\hline \multicolumn{7}{|l|}{ Delivery truck } \\
\hline \multicolumn{7}{|l|}{ Refuse truck } \\
\hline \multicolumn{7}{|l|}{$\begin{array}{l}\text { Bucket/utility } \\
\text { truck }\end{array}$} \\
\hline Semitrailer & [late 2020] & & & & & \\
\hline
\end{tabular}

1. Electric vehicle availability. Battery electric transit buses (BEBs) are available, and their market is established. There are at least 24 BEB manufacturers in Canada, China, Europe, India, and the United States (IEA 2019). Six of these have products available for sale in the United States: BYD, Gillig, Green Power, New Flyer, Nova, and Proterra.

2. Compatibility of routes and charging needs. Transit bus routes are compatible with charging needs. Transit buses run cyclical, repetitive routes with set schedules. Some cycle quickly, enabling frequent fast charges throughout the day. Others cycle more slowly, which is conducive to overnight charging at the depot. Most buses are available 
to charge in the middle of the night, when electricity demand tends to be lower and, in many cases, less expensive.

3. High kinetic intensity. Transit bus routes have a high kinetic intensity, which is a measure of the aggressiveness of the drive cycle (O-Keefe et al. 2007). The many stops and starts typical of transit routes is an indication of the potential efficiency benefit of electrification. EVs are at an efficiency advantage over diesel vehicles when stopping because they can recoup kinetic energy losses via regenerative braking. They are also at an advantage when accelerating from a stop because they operate optimally at a wide range of revolutions per minute (RPMs), as opposed to diesel engines that generally operate optimally at higher RPMs.

4. Idle reduction opportunity. Electrifying transit buses eliminates engine idling. Traditional vehicles need to power auxiliary loads (such as air conditioning) while stationary and typically need to idle their engines to do so. Idling diesel engines is a very inefficient way to power auxiliary loads (Gaines et al. 2006). Therefore, powering these loads with an electric motor saves a lot of fuel and greatly reduces emissions. Alternatively, vehicles that do not have auxiliary loads can turn their engines off and therefore do not benefit as much from an electric motor.

5. Valuation of ancillary benefits. Ancillary benefits of EVs are frequently valued by transit agencies, local governments, environmental justice advocates, passengers, and drivers. Transit buses travel in the country's most densely populated areas, where air quality and noise pollution are common concerns. These same areas are often nonattainment zones requiring emissions reductions that can be pursued through the use of EVs. In addition, the quick acceleration from low speeds is often valued by bus drivers that need to pull in and out of traffic frequently, and the overall quiet, low-vibration ride is valued by drivers and passengers alike.

6. Quantity of fuel consumed. Transit buses use more fuel per bus than any major vehicle category other than Class 8 trucks (AFDC 2018). They tend to drive many miles per year and have relatively low efficiency due to their heavy weight, resulting in average fuel use of over 10,000 gallons of diesel per year (AFDC 2018). Therefore, electrifying a transit bus can save more fuel than most other vehicle types.

The factors discussed above articulate reasons why transit buses are good candidates for electrification. However, transit fleets are run by fleet managers that need to consider the life cycle costs of purchasing this new technology in order to justify the high upfront costs. Therefore, the financial case needs to be laid out to show whether it makes economic sense to purchase a BEB.

Previous studies have compared the costs and benefits between BEBs and conventional fuel buses. Carnegie Melon University completed a study that weighed capital investment and lifetime operation costs, including infrastructure and bus depot modifications, and analyzed scenarios for fast- and depot-charging vehicles (Traffic21 Institute, 2017). A review of 12 assessments found that most studies analyzed costs including capital investments, operations costs, and infrastructure investments, while a small segment also included external costs such as 
environmental and health costs (Tong et al. 2017). The National Renewable Energy Laboratory (NREL) has led several evaluation studies that compared purchase costs, maintenance costs, and service costs on active BEB transit fleets in the United States (Eudy and Jeffers 2017).

The California Air Resources Board (CARB) developed a Transit Fleet Cost Model that allows comparison between different transit buses based on fuel technologies including compressed natural gas (CNG), diesel, diesel hybrid, battery electric, and fuel cell electric (CARB 2016). The CARB model also includes detailed input options for bus purchase price, maintenance costs, fuel costs, infrastructure costs, station upgrades, and electrical service upgrades and allows for manual manipulations of cost variables to better reflect an individual scenario based on California electric utility prices (CARB 2016).

These efforts have established a baseline for minimal requirements for cost variables to be included in an analysis. While these studies have been completed for individual fleet scenarios, and some even include multiple scenarios for different charging and funding mechanisms, the availability of comparison tools to analyze costs between BEBs and conventional fuel vehicles with options for an extensive range of inputs and charging scenarios remains limited.

The purpose of this project is to provide a financial analysis that can be generalized for transit fleets to help them determine under which conditions BEBs would be a good investment and to inform funding agencies that have the authority to identify which proposed projects would be the most fertile ground

This report provides a financial analysis that can be generalized for transit fleets to help them determine under which conditions BEBs would be a good investment. for funding. Furthermore, the model used for this analysis (Vehicle and Infrastructure Cashflow Evaluation model for Battery Electric Buses [VICE-BEB]) will be made available on the Alternative Fuels Data Center (AFDC) so that fleets across the United States can get a more personal assessment. Therefore, this report is a first step for transit agencies considering BEBs. The second step is to personalize the VICE-BEB to reflect their exact fleet, then subsequent steps include route analysis and consultation with the fleet's utility.

\section{Methodology}

This financial analysis is done through a discounted cashflow analysis (DCA), which is a common method for assessing investment options. The DCA compares purchasing new BEBs with purchasing comparable diesel buses. It takes the additional upfront cost into account and any fuel or maintenance savings over the life of the project. It discounts future money to account for inflation and the opportunity cost of alternative investments. The outputs of a DCA are net present value (NPV), discounted payback period, and simple (non-discounted) payback period.

NREL tuned its Vehicle and Infrastructure Cash-Flow Evaluation (VICE) model to run a DCA for BEB investments by transit bus fleets (called VICE-BEB). It runs specific scenarios for fleets and will be made available on the AFDC to any agency that wishes to evaluate their fleet. However, there are lessons to be learned by generalizing the analysis and determining the attributes of fleets for whom an investment in BEBs is likely to be cost-effective. These lessons are particularly valuable to two of the main audiences of the report: (1) transit authorities 
deciding whether to invest in BEBs and (2) funding agencies/partners trying to determine which fleets could likely execute a BEB grant project successfully.

This business case is developed through a six-part process, which is replicated in the structure of this report:

1. A literature search was done for other business cases or similar studies from which lessons could be learned.

2. A base-case fleet was developed to represent typical or average values for 35 key fleet attributes or inputs to the VICE model.

3. The model was run, reporting out NPV and discounted payback period of BEB and charger investment.

4. A sensitivity analysis was run to determine how sensitive the project NPV was to a $\pm 50 \%$ swing from the baseline value for each variable. Parameters were then ranked according to how influential they were on the NPV.

5. Parameters were grouped according to volatility, or the magnitude of likely swings. A volatility score was derived by dividing the range of plausible values by the baseline value. Six parameters that could not be quantified were still placed into volatility groups based on explained logic.

6. The influence and volatility rankings were combined, and the parameters that are both influential and volatile were highlighted. These parameters were then further investigated to learn how fleets might optimize the parameters and grantors might identify fleets with favorable parameters to invest in. In particular, the tradeoffs of fast chargers vs. depot chargers, along with the impact of electricity demand charges, is explored in greater depth.

\section{Baseline Scenario and Parameters}

In order to model a fleet that is as representative of as many real-life fleets as possible, we first need to define a baseline scenario. To do so, we had to determine a typical or average value for each of the 33 input parameters. The baseline scenario assumes depot charging (where buses are generally charged overnight) because all agencies reporting to the Transit Cooperative Research Program (TCRP) report have depot charging while only half have on-route conductive chargers and two have on-route wireless chargers. However, fast-charger projects were also analyzed in parallel to the baseline.

This analysis uses multiple input variables to simulate the financial circumstances faced by transit agencies. In this section, average or typical values are used to establish a baseline scenario for typical operating circumstances. This scenario provides a snapshot from which we can test the sensitivity of BEB project

Average or typical values are used to establish a baseline scenario for typical operating circumstances, then sensitivity analyses will be done on these parameters. economics with changes in various parameters. Table 2 provides a summary of the assumed 
input variables and their sources, which are further elaborated in the text below. The parallel project is a fast-charge scenario, where buses are generally charged in a matter of minutes multiple times per day. This fast-charge scenario has six parameters that differ from the depotcharge scenario, as highlighted at the bottom of Table 2.

Table 2. Baseline Parameters

\begin{tabular}{|c|c|c|c|c|}
\hline \multicolumn{5}{|c|}{ Baseline Parameters } \\
\hline & Parameter & Value & Unit & Source \\
\hline \multirow{6}{*}{ ד } & $\begin{array}{l}\text { Number of BEBs } \\
\text { obtained (total) }\end{array}$ & 4 & Vehicles & $\begin{array}{l}\text { Set to put the economics at a sensitive } \\
\text { threshold }\end{array}$ \\
\hline & Grant amount & $\$ 1,500,000$ & $\$$ & $\begin{array}{l}\text { Median of FY } 2018 \text { Low-No Bus Grant } \\
\text { Program (FTA 2018) }\end{array}$ \\
\hline & $\begin{array}{l}\text { Average life of bus (held } \\
\text { same for both bus types } \\
\text { to have consistent } \\
\text { project period) }\end{array}$ & 12 & years & $\begin{array}{l}\text { American Public Transit Association (APTA) } \\
\text { procurement guidelines (APTA 2013) }\end{array}$ \\
\hline & $\begin{array}{l}\text { Required rate of return } \\
\text { (RRR) or discount rate }\end{array}$ & $3.6 \%$ & $\%$ & $\begin{array}{l}\text { 5-year annual returns on Standard \& Poor's } \\
\text { municipal bond index (S\&P Global 2019) }\end{array}$ \\
\hline & $\begin{array}{l}\text { Average annual vehicle } \\
\text { miles traveled (VMT) }\end{array}$ & 32,814 & Miles/year & APTA (2018) \\
\hline & $\begin{array}{l}\text { Driver/attendant } \\
\text { refueling hours reduction }\end{array}$ & 0 & $\begin{array}{l}\text { Hours/ } \\
\text { week }\end{array}$ & $\begin{array}{l}\text { Assume that maneuvering buses is the same } \\
\text { for diesel or electric refueling }\end{array}$ \\
\hline \multirow{8}{*}{ 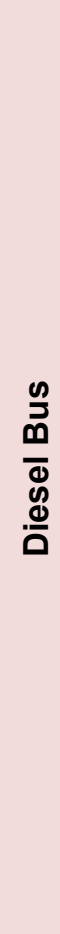 } & $\begin{array}{l}\text { Cost of new } 40-\mathrm{ft} \text { diesel } \\
\text { bus }\end{array}$ & $\$ 480,000$ & $\$$ & Standard diesel bus price (CARB 2016a) \\
\hline & $\begin{array}{l}\text { Fuel economy diesel } \\
\text { buses }\end{array}$ & 22.6 & $\mathrm{gal} / 100 \mathrm{mi}$ & $\begin{array}{l}\text { Altoona test of Gillig } 40-\mathrm{ft} \text { bus (Sturaa 2004). } \\
4.4 \mathrm{mpg}\end{array}$ \\
\hline & Diesel fuel price & $\$ 3.18 /$ gal & \$/gallon & U.S. annual 2018 price, (EIA 2019a) \\
\hline & Diesel price increase & $0.7 \% /$ year & $\% /$ year & Reference case 2018-2050 (EIA 2019b) \\
\hline & $\begin{array}{l}\text { Diesel vehicle } \\
\text { maintenance costs }\end{array}$ & $\$ 0.88 / \mathrm{mile}$ & $\$ / \mathrm{mi}$ & $\begin{array}{l}\text { Utilimarc Fleet Benchmarking database as } \\
\text { summarized in the Alternative Fuel Life- } \\
\text { Cycle Environmental and Economic } \\
\text { Transportation Tool (AFLEET 2018) }\end{array}$ \\
\hline & $\begin{array}{l}\text { Cost of operating a } \\
\text { diesel fuel station }\end{array}$ & \$0/year & \$/year & $\begin{array}{l}\text { Assume that the retail price of diesel } \\
\text { incorporates the amortized cost of running } \\
\text { the station }\end{array}$ \\
\hline & $\begin{array}{l}\text { Number of diesel buses } \\
\text { at facility where } \\
\text { recharge is to happen }\end{array}$ & 132 & buses & Average of 11 facilities surveyed \\
\hline & $\begin{array}{l}\text { Residual value of diesel } \\
\text { bus }\end{array}$ & $15.0 \%$ & $\begin{array}{l}\% \text { of } \\
\text { purchase } \\
\text { price }\end{array}$ & Hensher (2007) \\
\hline
\end{tabular}




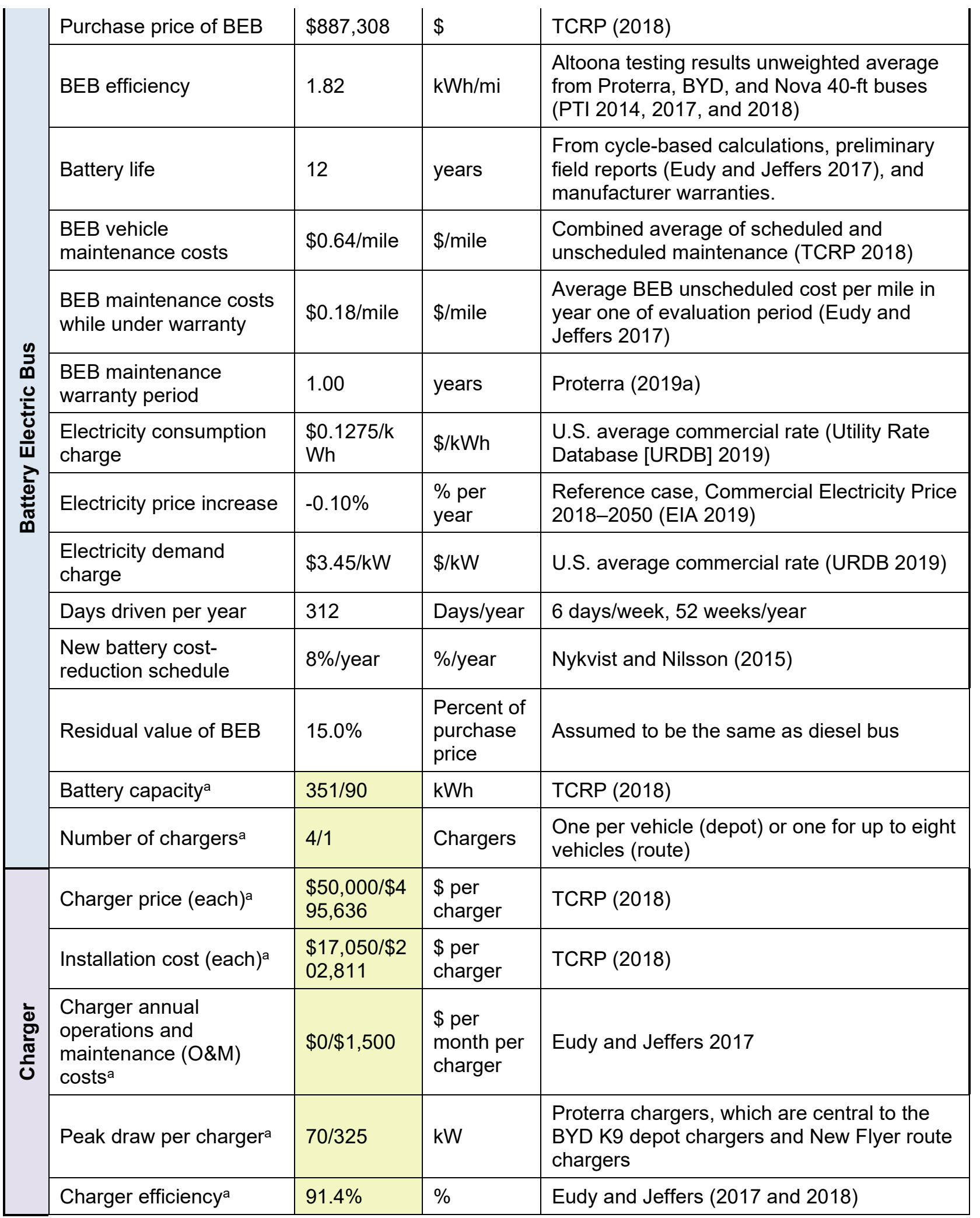

a Items highlighted in yellow have two distinct values for depot charge (left) and fast charge (right) projects. 


\section{General Costs}

- RRR or discount rate: The discount rate was determined based on the 5-year annual returns on the S\&P Municipal Bond Index in April 2019 (S\&P Global 2019).

- Average vehicle miles traveled: The average annual VMT for transit buses was calculated from statistics found in APTA's Public Transportation Fact Book 2018 (APTA 2018).

- Number of BEBs obtained (total): The number of buses obtained was based on analysis gathered from 220 publicly announced fleet orders in the United States. While the average number of buses purchased by fleets was 4.7 , the most typical purchase number for a fleet was one vehicle. For this analysis, the baseline input was rounded down from the average to account for this difference.

- Grant amount: The grant amount was based on the median award for the Fiscal Year 2018 Federal Transit Administration (FTA) Low or No Emissions Bus Grants (FTA 2018). $\$ 1.5 \mathrm{M}$ for four buses is $\$ 375,000$ per bus.

- Average life of bus: The average life of a bus was held constant for BEBs and diesel buses, so the analysis would have a consistent project period. This number was chosen based on average useful bus life information provided in the APTA procurement guidelines (APTA 2103).

\section{Diesel Bus Costs}

- Cost of new 40-ft diesel bus: The cost of a new standard diesel transit bus was gathered from the CARB Transit Agency Committee Cost subgroup. This analysis used the standard diesel bus price for the latest year gathered (CARB 2016a).

- Fuel economy diesel buses: Fuel economy was taken from the overall average fuel consumption results from the Gillig 40-ft low floor bus as tested by the Pennsylvania Transportation Institute (PTI) (PTI 2004). The Gillig bus was chosen because it is one of the most common buses in the United States and has a relatively recent Altoona test.

- Diesel fuel price: Diesel fuel price was based on average 2018 retail fuel prices in the United States (EIA 2019a). The Gulf region price was used as the low price because it is the lowest-cost region in the United States. The San Francisco price was used as the high price. Retail prices were used instead of wholesale or contract prices because they account for the cost of operating a diesel station, which most fleets do.

- Diesel price increase: Diesel price increases were gathered from the EIA's 2019 Annual Energy Outlook diesel fuel price growth (reference case) from 2018-2050 (EIA 2019b).

- Diesel vehicle maintenance: Maintenance costs were based on the Utilimarc Fleet Benchmarking database, as summarized in the AFLEET tool (AFLEET 2018).

- Cost of operating a diesel fuel station: We used retail diesel prices for all fleets, regardless of if they purchased from a retailer or operated their own station. This pricing assumed that the costs of operating a diesel station are approximately the same as the margin made by retailers. This profit margin is very slim for retailers, and most of it goes back into station operation (National Association of Convenience Stores 2019).

Therefore, a fleet will pay the same amount for fuel regardless if they pay a margin to a third party or spend that same amount operating their own diesel station.

- Attendant/driver hourly wage: Bus driver hourly wage was based on a Bureau of Labor Statistics (BLS) national estimate for transit and intercity bus drivers in 2017 (BLS 2017). 
- Attendant/driver hours reduced weekly: The analysis assumed that the time spent to refuel at a fast-charging station is equal to the time spent to refuel a diesel vehicle. For depot charging, it is assumed that the vehicles will be charged at night when drivers are not working. For both scenarios, the hours reduced was kept at zero.

- Number of diesel buses at depot where recharge is to happen: NREL surveyed 11 transportation authorities throughout the United States to determine the average number of transit buses being serviced by a depot.

- Residual value of diesel bus: The residual value of a diesel bus was based on information from Bus Transport: Economics, Policy, and Planning (Hensher 2007).

\section{BEB Costs}

- Purchase price of BEB: The purchase price of a BEB was based on the average cost per bus in the TCRP Synthesis 130 report (TCRP 2018). This price was assumed to be the same for all BEBs, regardless of battery range and charging type. The TCRP report pulls from the limited and rapidly changing U.S. transit bus market and therefore could be outdated quickly.

- Battery capacity: Batter capacity was based on the TCRP Synthesis 130 report overview of BEB manufacturers and products (TCRP 2018). Average battery capacity was collected for depot-charge vehicles and on-route charge vehicles separately to develop two different baselines. Any BEBs that were identified as depot and on-route combined were put into the depot-charge average.

- BEB efficiency: Efficiency data were gathered from results of three different manufacturers' vehicles at the Altoona Bus Research and Testing Center. The average efficiency from each bus test was then averaged together for a combined average BEB efficiency (PTI 2014, 2017, and 2018). The air conditioner and heater are not used in Altoona tests, as discussed in the volatility section of this report.

- Days per year driven: It was assumed that vehicles are driven 6 days per week, 52 weeks per year.

- Battery life (years): Battery life was determined based on results from a recent BEB study estimating that batteries may last up to 12 years (Eudy and Jeffers 2017). In addition, both BYD (Mass Transit 2015) and Proterra (Proterra 2019b) offer 12-year warranties on their batteries, ensuring that batteries can last that long without additional investment. New Flyer warranties their batteries for 6 years with an option to extend to 12 years. Furthermore, BEB manufacturers are taking additional steps to ensure that transit companies won't need to replace batteries before the end of bus life by offering battery lease options (Blanco 2019).

- New battery cost-reduction schedule: The cost decline of battery packs was assumed to be $8 \%$ for major manufacturers, as reported in Nykvist and Nilsson (2015).

- Residual value of BEB: The residual value of a BEB was assumed to be the same as for a diesel bus. The residual value of the battery was calculated separately. See Residual value of diesel bus.

- BEB vehicle maintenance costs: Vehicle maintenance costs were gathered from the TCRP Synthesis 130 report. An average was taken of the scheduled and unscheduled maintenance costs (TCRP 2018). 
- BEB maintenance warranty period: This analysis assumed that manufacturers offer a one-year maintenance warranty like Proterra does (Proterra 2019a).

- BEB maintenance costs while under warranty: Maintenance costs while under warranty were based on the unscheduled cost of maintenance in year one of bus ownership from the Foothill Transit bus demonstration, assuming that the scheduled maintenance costs are covered by the manufacturer through the warranty. Year one costs are representative because the Foothill buses were still under manufacturer warranty during that time (Eudy and Jeffers 2017).

- Electricity consumption charge (per $k W h$ ): The electricity consumption charge (per $\mathrm{kWh}$ ) was calculated from NREL analysis on over 12,000 current commercial utility rates across diverse geographic areas in the United States. All rate information was gathered from the URDB (2019).

- Electricity price increase: Projected electricity price increases were taken from the EIA's 2019 Annual Energy Outlook commercial electricity price growth (reference case) from 2018-2050 (EIA 2019b).

- Cost of battery (current): The cost of batteries was based on the 2015 U.S. Department of Energy estimate of $\$ 268 / \mathrm{kWh}$ (Howell et al. 2016). This cost was used in the residual value calculation only and did not affect the purchase price of a BEB.

\section{Charger Cost}

For charger parameters, the analysis relies on two different scenarios: a depot-charging and an on-route fast-charging scenario. For the parameters discussed below, both scenarios will be addressed.

- Number of chargers: The analysis assumed that for depot-charge vehicles, one charger will be needed for each vehicle purchased. This implicitly assumes that sequential timing will not be used, which allows for maximum flexibility when pairing charge timing to off-peak loads. For the fast-charging scenario, it is assumed that one fast charger can support up to eight buses. This is based on the highest ratio observed by a fleet in the TCRP Synthesis 130 report (2018).

- Charger price (each): Charger price was based on the TCRP Synthesis 130 report. The average cost for depot-charging equipment was used in the depot scenario, and the average cost for on-route charging equipment was used in the fast-charging scenario (TCRP 2018).

- Installation cost (each): Charger installation was based on the TCRP Synthesis 130 report. The average installation cost for depot-charging equipment was used in the depot scenario, and the average installation cost for on-route charging equipment was used in the fast-charging scenario (TCRP 2018).

- Charger annual operations and maintenance costs: Charger O\&M costs were based on findings from the Foothill Transit BEB demonstration. Foothill Transit has a contract with the charger manufacturer to maintain the fast chargers for $\$ 1,500 /$ month. It was assumed that depot chargers have limited monthly costs, so the baseline for the bus depot charging is zero (Eudy and Jeffers 2017).

- Charger life: Charger life was set to the same as bus life in the base case. This allowed us to model the project as one temporal unit with the purchase of all equipment in a given year and the retirement of all equipment at the same time. 
- Charger salvage value: Charger salvage value, as a percent of purchase value, was set to the same for electric and diesel buses. This assumption was made due to a lack of research into this topic because chargers have not been around for very long.

- Charger efficiency: Chargers were assumed to be $91.4 \%$ efficient. This is an average of Foothill Transit fast chargers (Eudy and Jeffers 2017) and County Connection Depot Chargers (Eudy and Jeffers 2018). Fast and depot chargers were assumed to have the same efficiency because we do not have enough data to differentiate and do not want to skew the comparison between fast and depot chargers.

\section{Electricity Demand Charges}

Electricity demand charges are costs based on the power (measured in kilowatts [kW]) rather than total energy (measured in kilowatt-hours $[\mathrm{kWh}]$ ). They are typically charged based on the highest 15-minute or hourly interval over the course of a monthly billing period. Over $40 \%$ of commercial rates in the United States have demand charges (URDB 2019). In 2019, the average demand charge for commercial rates in the United States based on the URDB is $\$ 3.45 /$ kilowatt. For bus fleets, the demand charges for electricity can be a substantial cost component of operating BEBs. Therefore, a fleet should include an analysis of added electric load, as it relates both to energy $(\$ / \mathrm{kWh})$ and demand charges $(\$ / \mathrm{kW})$.

This analysis assumes that chargers are metered together with the facility, which could enable the fleet manager to reduce the impact buses will have on demand charges by adjusting what time buses charge. The amount that BEBs will increase a bus facility's peak demand depends on a number of factors: the number of buses, number of chargers, and type of chargers.

Furthermore, the extent to which BEBs will increase a bus facility's peak demand depends on the timing of charge and the ability to co-locate the charging infrastructure with an existing electricity load at the facility, as demonstrated in Figure 1. 


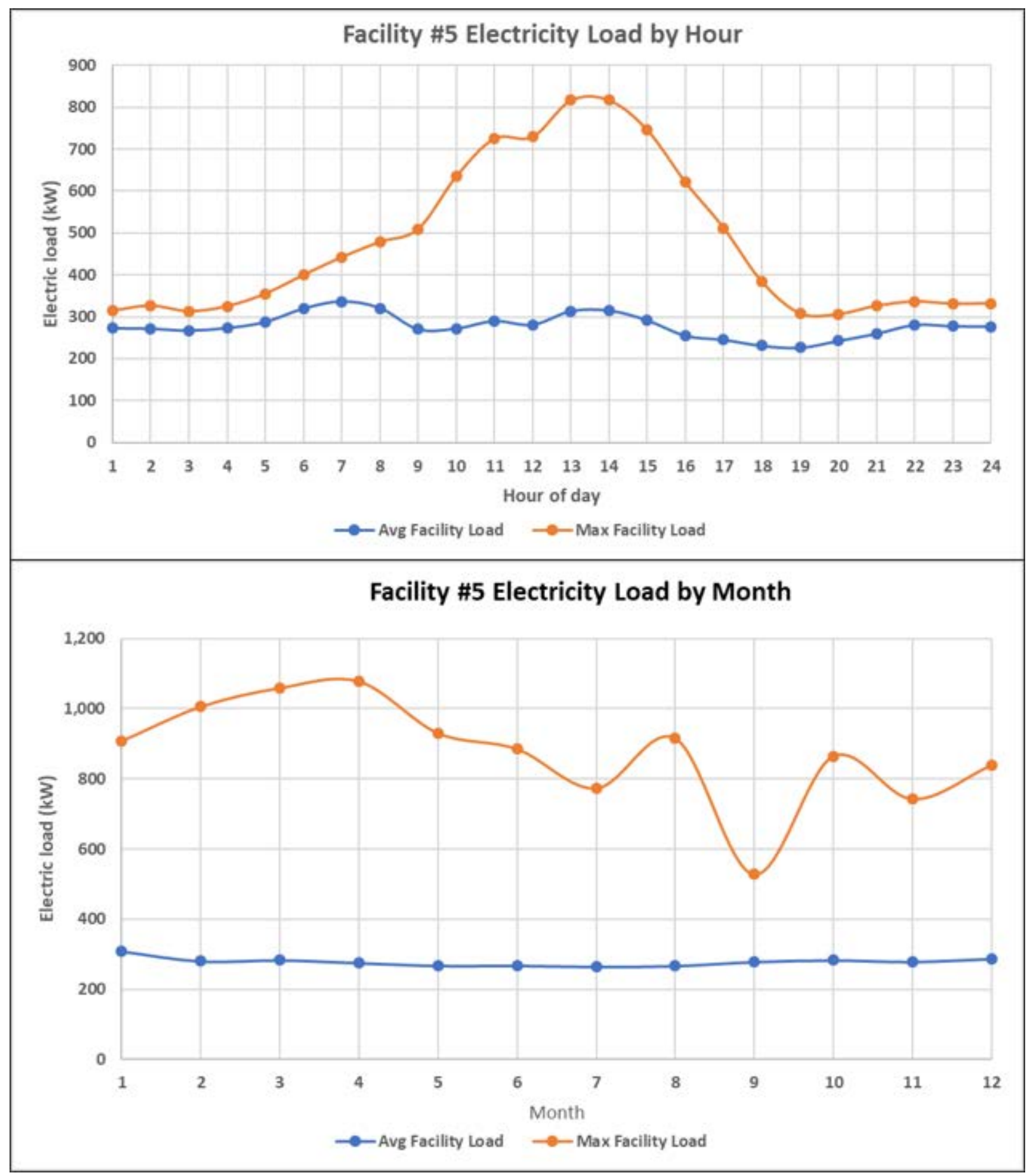

Figure 1. Hourly and monthly electrical load profiles for a diesel bus facility with no BEBs Data source: Eichman et al. (forthcoming)

In the example shown in Figure 1, if buses charge between 7 p.m. and 5 a.m., where the average load is $\sim 300 \mathrm{~kW}$, the facility can handle an additional $500-\mathrm{kW}$ charger load without increasing the $\sim 800 \mathrm{~kW}$ peak load. As a result, if the demand charge was billed on the highest daily peak demand, the site would not see an increase in demand charges based on the additional BEB load. This amount is understated when looking at the average day because the monthly peak is often 
higher than the daily average peak. This can be seen by comparing Facility \#5's average daily peak $(800 \mathrm{~kW}$ ) to the average monthly peak (as high as $1,100 \mathrm{~kW}$ ). For this analysis, we assume that charging can be managed so that any BEB load that is added to the average facility load (blue lines) will not increase peak load until it surpasses the average monthly load maximum (orange line). In other words, the delta between the average and peak monthly load will incur no additional demand charge. While not always possible to optimize timing, agencies can make improvements by assessing major loads such as bus wash, maintenance activities, and CNG compressors.

In order to determine the delta between average and peak loads, NREL surveyed 11 facilities that could potentially host BEB chargers. These included bus yards, depots, garages, and combinations thereof. Some of these facilities have administrative offices and diesel stations on site. None of the facilities

Electricity demand charges are modeled under simplified conditions; it is assumed that BEB charging is done when the facility is at average electric load surveyed included CNG stations, which have a large demand that could complement chargers (though more research is necessary). The average of monthly peak-average load deltas across all months and all facilities was $206 \mathrm{~kW}$, so the base case implicitly assumes that $206 \mathrm{~kW}$ of load from bus charging could be added to a given facility without incurring any additional demand charges. However, this delta is highly dependent upon the size of the facility, so a representation of size was needed in order to make the model more scalable. The best representation is the number of diesel buses that the facility currently hosts and services. When the delta between average and peak monthly load is pegged to the number of buses at a facility, each bus increases the delta by $1.54 \mathrm{~kW}$.

To summarize in equation form, the incremental increase in monthly demand charges incurred by adding BEBs to an existing facility are calculated as such, followed by their baseline inputs:

where

Increase in Monthly Demand Charge $=$ Electricity Demand Charge $*(B E B$ Peak Load - Monthly Load Delta $)$

$$
\text { BEB Peak Load }=\text { Number of Chargers } * \text { Peak Draw per Charger }
$$

and

Monthly Load Delta $=$ Number of Diesel Buses at Facility $*$ Load Delta per Bus

This equation assumes that the time period where the delta between peak and average load is long enough to fully charge the BEBs.

- Electricity demand charge: The price of electricity (per $\mathrm{kW}$ ) was calculated from NREL analysis on over 12,000 current commercial utility rates across diverse geographic areas in the United States. There is a vast diversity of rate structures, including ones that are negotiated for specific customers, so we were not able to focus solely on the rates of potential electric bus owners. The baseline was calculated including rates with zero demand charges because $59 \%$ of the rates analyzed, including those of some prominent $\mathrm{BEV}$ fleets, did not have demand charges. All rate information was gathered from the URDB (2019) and checked against rates reported to NREL through survey and technical assistance projects. 
- Peak draw per charger: For this analysis, Proterra chargers were used for both depot and on-route charging estimates. This is because Proterra chargers were central to the BYD and New Flyer options on the market and represent real chargers available to purchase rather than the average size of a charger (Proterra 2019b).

- Number of diesel buses at facility: The number of diesel buses at the facility was taken from our survey of 11 facilities. These facilities include bus yards, depots, garages, and combinations thereof. Some included administrative offices and diesel stations.

- Load delta per bus: The load delta per bus was taken from our survey of 11 facilities.

- Number of chargers: This is described in the charger section.

\section{Calculated Parameters}

Additional parameters that are calculated in the model include the following:

- Annual diesel use

- Incremental cost of all vehicles (BEBs more than diesel buses)

- Annual electricity use

- Monthly electricity use

- Battery range

- Distance driven per day

- Charges per day

- Battery replacement cost.

These parameters are calculated based on the other model inputs mentioned above and do not have a separate source reference outside of this model. Details on the calculations of these parameters can be found in the Appendix.

\section{NPV and Payback of Baseline Scenario}

The cumulative cashflow from the investment, by year, is displayed in Figure 2. At the start of the project (year zero), the cashflow is negative $\$ 322,000$ because the upfront cost of four BEBs and depot chargers, despite the $\$ 1.5$ million grant, is still greater than the cost of purchasing four diesel buses. However, this deficit is reduced over the next 12 years as the fleet accumulates savings from fuel and maintenance costs. These savings accumulate particularly quickly in the first year of the project (because the BEB warranty reduces maintenance costs lower that year than others) and the last year of the project (because BEB and charger salvage values are worth more than the salvage values of diesel buses, due to the fact that their upfront costs are greater). The project deficit is recovered after 3.6 years (the discounted payback period). At this point, the investment has surpassed the RRR. Many analysts focus on the simpler nondiscounted payback period, which is 3.4 years. The NPV for the entire project is $\$ 785,000$.

NPV for the baseline scenario is $\$ 785,000$, with a discounted payback of 3.6 years. 


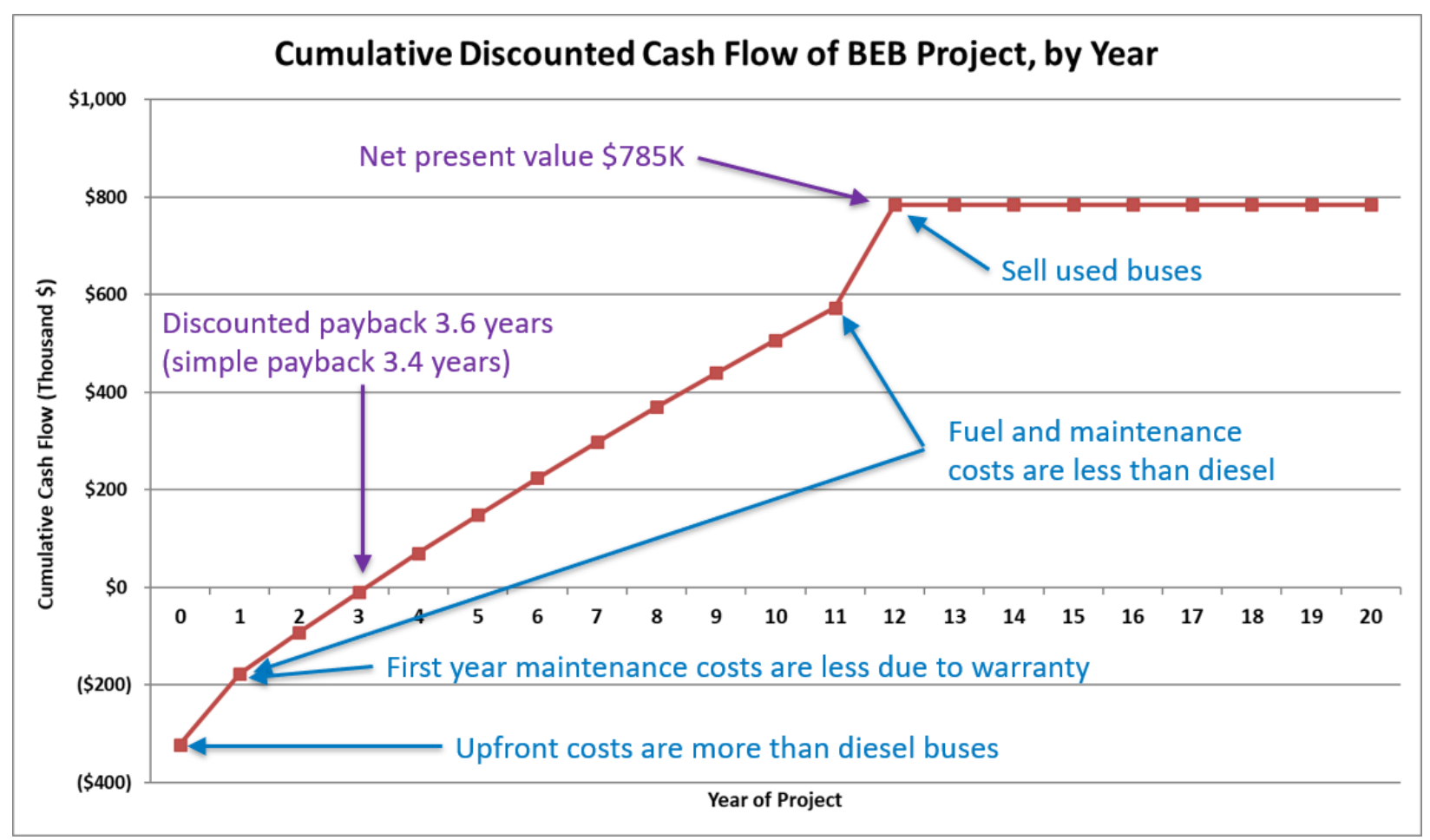

Figure 2. Cumulative discounted cashflow of depot-charge BEB project by year parameter influence

The same process was used to analyze fast-charge buses and an on-route fast charger. The NPV of the baseline scenario with one fast charger instead of four depot chargers was $\$ 308,000$, with a discounted payback of 9.8 years and simple payback of 8.3 years. This is a substantially less positive investment than the project with depot chargers due to the more expensive charger, installation, and maintenance costs. However, there are conditions where a fast charger can be cost-effective, as explored in the Depot vs. Fast Chargers section.

\section{Parameter Influence}

Some parameters have a much larger influence on project economics than others. In order to determine which parameters are the most influential, we swung each of them $\pm 50 \%$ from their baseline value (Table 2) and recorded the resulting swing in NPV. These swings are shown in Table 3. Parameter influence is the same for both depot and fast chargers unless explicitly stated. Sometimes the $\pm 50 \%$ swing resulted in an unrealistic parameter, which will be addressed in the volatility section of this report. 
Table 3. The Swing in NPV Resulting from a $\pm 50 \%$ Swing in Each Parameter

\begin{tabular}{|c|c|c|c|}
\hline Rank & Category & Parameter & $\begin{array}{l}\text { NPV } \\
\text { Swing }\end{array}$ \\
\hline 1 & Electric Bus & Purchase price of BEB & $\$ 3,200,968$ \\
\hline 2 & Diesel Bus & Purchase price of new $40-\mathrm{ft}$ diesel bus & $\$ 1,731,602$ \\
\hline 3 & General & Grant amount & $\$ 1,500,000$ \\
\hline 4 & Diesel Bus & Diesel vehicle maintenance & $\$ 1,129,599$ \\
\hline 5 & General & Average VMT & $\$ 1,033,894$ \\
\hline 6 & Diesel Bus & Diesel fuel price & $\$ 958,087$ \\
\hline 7 & Diesel Bus & Fuel economy diesel buses & $\$ 958,087$ \\
\hline 8 & General & Average life of bus & $\$ 757,423$ \\
\hline 9 & Electric Bus & Number of BEBs obtained $\left(\operatorname{depot}^{\mathrm{a}}\right)$ & $\$ 771,923$ \\
\hline 10 & Electric Bus & BEB vehicle maintenance costs & $\$ 698,440$ \\
\hline 11 & Charger & Charger price $\left(\right.$ fast $^{\mathrm{a}}$ ) & $\$ 495,636$ \\
\hline 12 & Electric Bus & Number of BEBs obtained (fast ${ }^{\mathrm{a}}$ ) & $\$ 404,101$ \\
\hline 13 & Electric Bus & Electric bus efficiency & $\$ 320,804$ \\
\hline 14 & Electric Bus & $\begin{array}{l}\text { Electricity consumption charge (per } \\
\text { kWh) }\end{array}$ & $\$ 320,734$ \\
\hline 15 & Electric Bus & Residual value of BEB & $\$ 311,343$ \\
\hline 16 & General & $\mathrm{RRR}$ or discount rate & $\$ 258,310$ \\
\hline 17 & Charger & Installation price (fast ${ }^{\mathrm{a}}$ ) & $\$ 202,811$ \\
\hline 18 & Charger & Charger price $\left(\right.$ depot $\left.^{\mathrm{a}}\right)$ & $\$ 200,000$ \\
\hline 19 & Diesel Bus & Residual value of diesel bus & $\$ 188,398$ \\
\hline 20 & Charger & Peak charger draw $\left(\right.$ fast $^{\mathrm{a}}$ ) & $\$ 115,074$ \\
\hline 21 & Electric Bus & BEB maintenance warranty period & $\$ 110,554$ \\
\hline 22 & Charger & Peak charger draw $\left(\operatorname{depot}^{\mathrm{a}}\right)$ & $\$ 87,745$ \\
\hline 23 & Charger & Electric load delta (fast $^{\mathrm{a}}$ ) & $\$ 82,303$ \\
\hline 24 & Electric Bus & Battery life (years) & $\$ 77,714$ \\
\hline 25 & Charger & Electric load delta $\left(\operatorname{depot}^{\mathrm{a}}\right)$ & $\$ 72,214$ \\
\hline 26 & Charger & Charger installation cost (each, depot ${ }^{\mathrm{a}}$ ) & $\$ 68,200$ \\
\hline 27 & Electric Bus & $\begin{array}{l}\text { Electricity demand charge (per kW) } \\
\text { (fast }{ }^{\mathrm{a}} \text { ) }\end{array}$ & $\$ 49,282$ \\
\hline 28 & Diesel Bus & Diesel price increase & $\$ 37,667$ \\
\hline 29 & Electric Bus & $\begin{array}{l}\text { BEB maintenance costs while under } \\
\text { warranty }\end{array}$ & $\$ 34,618$ \\
\hline 30 & Electric Bus & $\begin{array}{c}\text { Electricity demand charge (per kW) } \\
\left(\operatorname{depot}^{\mathrm{a}}\right)\end{array}$ & $\$ 31,062$ \\
\hline 31 & Charger & Charger efficiency & $\$ 25,399$ \\
\hline 32 & Electric Bus & Battery capacity & $\$ 18,185$ \\
\hline 33 & Charger & Charger maintenance costs (fast ${ }^{\mathrm{a}}$ ) & $\$ 14,669$ \\
\hline 34 & Electric Bus & Electricity price increase & $\$ 1,785$ \\
\hline
\end{tabular}

a "Fast" and "depot" at the end of the parameter name demarks that parameter is specifically part of a fast-charge or depot-charge project.

The three most influential parameters all directly impact the upfront investment cost of the project. Upfront costs are not discounted by time, so their impact is not reduced the way future costs are. The influence of these parameters is relative to the magnitude of their baseline value. 
The BEB is the largest investment by amount, so swinging its price $\pm 50 \%$ has the largest impact on NPV. The price of the foregone diesel bus is less than the BEB, so its impact is less (and inverse, as an expensive diesel bus actually improves the NPV of a BEB project). The grant amount is less influential than either of the bus costs because it is less than the investment in four buses of either type.

The next five most influential parameters impact the annual operating costs of either the BEB fleet or the foregone diesel fleet. These are highly influential because they accrue savings for 12 years. Like the three upfront costs, the impact of these operational cost

The three most influential parameters are related to upfront costs; the next five impact the annual operating costs parameters is also relative to their magnitude.

The fuel price and vehicle fuel economy have the same impact because raising either one $50 \%$ has the same impact on fuel expenditures. This is the same for both diesel and electricity. However, these components of diesel expenditures are three times more influential than for their electric counterparts.

When considering electricity demand charges, the electric load delta for the facility hosting the charger is three times more influential than the demand charge $(\$ / \mathrm{kW})$ set by the utility. All differences between depot- and fast-charge projects will be addressed in the Depot vs. Fast Chargers section.

The least influential parameter of those tracked is the projected change in the electricity consumption charge $(\$ / \mathrm{kWh})$. This is partially because the additional costs are not incurred until later in the project cycle (when costs are greatly discounted) and partially because the price is low to begin with. Future diesel prices are 23 times more influential than future electricity prices but still relatively low on the list because they are also not incurred until later in the project life.

\section{Parameter Volatility}

The previous section illustrated the impact that each parameter can have on project economics when swung $\pm 50 \%$, but that is only half of the equation. We also need to know the likelihood of such a swing or the likely magnitude of future swings. In other words, we need to know the volatility of each parameter. To calculate this, we researched past maximum and minimum values for each parameter, as shown in Table 4 . We then determined a volatility score based on the equation below and ranked them by this score. All parameters were grouped into three categories of volatility:

The volatility of a project parameter reflects how variable or uncertain it is high, medium, or low. Six of the parameters had insufficient data to determine a volatility score, so they were ranked based on a logic that is documented on the right side of Table 4. All parameters are the same for depot- and fast-charge investments unless noted in the parameter name.

$$
\text { Volatility Score }=\frac{\text { Max }- \text { Min }}{\text { Baseline }}
$$


Table 4. Volatility for BEB and Charger Investment

\begin{tabular}{|c|c|c|c|c|c|}
\hline Parameter & $\begin{array}{l}\text { Baseline } \\
\text { Input }\end{array}$ & Input Range & $\begin{array}{l}\text { Volatility } \\
\text { Score }\end{array}$ & $\begin{array}{l}\text { Volatility } \\
\text { Rating }\end{array}$ & Source/Logic \\
\hline Number of BEBs obtained & 4 & 1 to 84 & 20.75 & High & $\begin{array}{c}\text { TCRP Synthesis Report } 130 \\
(2018)\end{array}$ \\
\hline Electricity demand charge & $\$ 3.45 / \mathrm{kW}$ & $\begin{array}{l}\$ 0.00 \text { to } \\
\$ 21.68 / \mathrm{kW}\end{array}$ & 6.28 & High & $\begin{array}{l}\text { State average with the highest } \\
\text { average demand charge from all } \\
\text { utility maximum charges. URDB } \\
(2019) \text { and McLaren (2017) }\end{array}$ \\
\hline Electricity price increase & $-0.1 \%$ & $-0.4 \%$ to $+0.2 \%$ & 6.00 & High & $\begin{array}{l}\text { High and low scenarios to } 2050 \\
\text { (EIA 2019) }\end{array}$ \\
\hline Diesel price increase & $0.7 \%$ & $-0.7 \%$ to $+0.2 \%$ & 4.29 & High & $\begin{array}{c}\text { High and low scenarios to } 2050 \\
\text { (EIA 2019) }\end{array}$ \\
\hline $\begin{array}{l}\text { BEB maintenance warranty } \\
\text { period }\end{array}$ & 1 year & 1 to 5 years & 4.00 & High & $\begin{array}{c}\text { Warranty info from BYD, Proterra, } \\
\text { and New Flyer }\end{array}$ \\
\hline $\begin{array}{l}\text { Charger installation cost } \\
\text { (each) }\end{array}$ & $\$ 17 \mathrm{~K}$ & $\$ 2 \mathrm{~K}$ to $\$ 64 \mathrm{~K}$ & 3.64 & High & TCRP (2018) \\
\hline Electric load delta & $203 \mathrm{~kW}$ & 693 to $27 \mathrm{~kW}$ & 3.28 & High & 11 surveyed depots \\
\hline RRR or discount rate & $3.6 \%$ & $0.0 \%$ to $10.0 \%$ & 2.78 & High & $\begin{array}{c}\text { Some do not consider discount, } \\
\text { some expect } 10 \%\end{array}$ \\
\hline BEB maintenance costs & $\$ 0.64 / \mathrm{mi}$ & $\$ 0.18$ to $\$ 1.47 / \mathrm{mi}$ & 2.02 & High & TCRP $(2018)$ \\
\hline Charger price (depot) & $\$ 50 \mathrm{~K}$ & $\$ 2 \mathrm{~K}$ to $\$ 100 \mathrm{~K}$ & 1.96 & High & TCRP (2018) \\
\hline Charger installation (fast) & $\$ 203 \mathrm{~K}$ & $\$ 50 \mathrm{~K}$ to $\$ 400 \mathrm{~K}$ & 1.73 & Medium & TCRP (2018) \\
\hline Battery capacity & $351 \mathrm{kWh}$ & 94 to $660 \mathrm{kWh}$ & 1.61 & Medium & Proterra website \\
\hline $\begin{array}{c}\text { Number of diesel buses at } \\
\text { charger depot }\end{array}$ & 132 & 26 to 236 & 1.59 & Medium & 11 surveyed depots \\
\hline Diesel vehicle maintenance & $\$ 0.88 / \mathrm{mi}$ & $\$ 0.37$ to $\$ 1.71 / \mathrm{mi}$ & 1.52 & Medium & Utilimarc, via AFLEET (2018) \\
\hline Grant amount & $\$ 1.5 \mathrm{M}$ & $\$ 403 \mathrm{~K}$ to $\$ 2.29 \mathrm{M}$ & 1.43 & Medium & $\begin{array}{c}\text { FTA (2018) and California HVIP } \\
(2019)\end{array}$ \\
\hline Peak charger draw (depot) & $70 \mathrm{~kW}$ & 40 to $120 \mathrm{~kW}$ & 1.14 & Medium & TCRP $(2018)$ \\
\hline Electricity consumption charge & $\$ 0.1275 / \mathrm{kWh}$ & $\begin{array}{c}\$ 0.057 \text { to } \\
\$ 0.172 / \mathrm{kWh}\end{array}$ & 0.90 & Medium & $\begin{array}{l}\text { URDB (2019): Top and bottom } \\
\text { quintile }\end{array}$ \\
\hline Peak charger draw (fast) & $325 \mathrm{~kW}$ & 300 to $450 \mathrm{~kW}$ & 0.84 & Medium & New Flyer (2019) \\
\hline BEB purchase price & $\$ 887,308$ & $\$ 579 \mathrm{~K}$ to $\$ 1.2 \mathrm{M}$ & 0.70 & Medium & TCRP $(2018)$ \\
\hline BEB efficiency & $1.82 \mathrm{kWh} / \mathrm{mi}$ & $\begin{array}{c}1.70 \text { to } 2.84 \\
\mathrm{kWh} / \mathrm{mi}\end{array}$ & 0.63 & Medium & $\begin{array}{c}\text { PTI (2007) and Eudy and Jeffers } \\
(2018)\end{array}$ \\
\hline Charger price (fast) & $\$ 495,636$ & $\$ 330 \mathrm{~K}$ to $\$ 600 \mathrm{~K}$ & 0.54 & Medium & TCRP $(2018)$ \\
\hline Average annual VMT & $\begin{array}{c}32.8 \mathrm{~K} \\
\mathrm{mi} / \text { year }\end{array}$ & $\begin{array}{c}25 \mathrm{~K} \text { to } 40 \mathrm{~K} \\
\text { mi/year }\end{array}$ & 0.46 & Medium & Levy (2019) \\
\hline Residual value of BEB & $15 \%$ & Unavailable & Qualitative & Low & $\begin{array}{c}\text { Depends on battery. Second-hand } \\
\text { market unknown. }\end{array}$ \\
\hline Fuel economy diesel buses & $\begin{array}{c}22.57 \\
\mathrm{gal} / 100 \mathrm{mi}\end{array}$ & $\begin{array}{c}22.57 \text { to } 30.86 \\
\text { gal } / 100 \mathrm{mi}\end{array}$ & 0.37 & Low & $\begin{array}{l}\text { Gillig and New Flyer, (74\% of } \\
\text { market) (PTI } 2004 \text { and 2007) }\end{array}$ \\
\hline Diesel fuel price & $\$ 3.18 /$ gal & $\$ 2.96$ to $\$ 3.87 / \mathrm{gal}$ & 0.28 & Low & EIA 2019a, Gulf and CA \\
\hline Charger efficiency & $91.4 \%$ & $79.5 \%$ to $94 \%$ & 0.16 & Low & $\begin{array}{l}\text { Least efficient and most efficient } \\
\text { months for depot and fast } \\
\text { chargers (Eudy and Jeffers } 2017 \\
\text { and 2018) } \\
\end{array}$ \\
\hline Cost of new $40-\mathrm{ft}$ diesel bus & $\$ 480 K$ & $\$ 430 \mathrm{~K}$ to $\$ 496 \mathrm{~K}$ & 0.14 & Low & $\begin{array}{l}\text { Washington State contract and } \\
\text { MTA purchase (MTA 2014) }\end{array}$ \\
\hline
\end{tabular}




\begin{tabular}{|c|c|c|l|l|c|}
\hline Battery life & 12 years & Unavailable & Qualitative & Low & $\begin{array}{c}\text { 12-year battery warranties } \\
\text { (Proterra 2019b) }\end{array}$ \\
\hline Average life of bus & 12 years & Unavailable & Qualitative & Low & $\begin{array}{c}\text { Buses built and scheduled for 12 } \\
\text { years }\end{array}$ \\
\hline Number of chargers & 4 (=\# buses) & Unavailable & Qualitative & Low & $\begin{array}{c}\text { Sharing chargers would incur } \\
\text { labor costs }\end{array}$ \\
\hline Residual value of diesel bus & $15.0 \%$ & Unavailable & Qualitative & Low & $\begin{array}{c}\text { Buses designed for 12 years then } \\
\text { sold to scrap markets }\end{array}$ \\
\hline $\begin{array}{c}\text { BEB maintenance costs while } \\
\text { under warranty }\end{array}$ & $\$ 0.18 / \mathrm{mi}$ & Unavailable & Qualitative & Low & $\begin{array}{c}\text { Scheduled maintenance is } \\
\text { predictable }\end{array}$ \\
\hline
\end{tabular}

Most of the parameters' volatility is due to fleet choices and other characteristics that can be managed or influenced by the fleet. Fleets can focus on these to position themselves for a costeffective BEB investment. Other parameters vary based on geographical location. These parameters include electricity price, demand charge, diesel price, and charger installation costs. Funding agencies could take these factors into account when deciding which fleets are more likely to execute successful projects. Finally, some parameters vary primarily over time. These include diesel price, BEB cost, BEB maintenance costs, fuel economy of diesel buses, and battery life.

\section{Key Parameters When Considering BEB Investment}

Combining the influence and volatility rankings of each parameter helps indicate which parameters to prioritize when considering a BEB investment. Table 5 shows the top parameters when ranking both on influence and volatility. In particular, all low-volatility parameters with an NPV swing of less than \$1 million were omitted, all medium-volatility parameters with an NPV less than $\$ 315,000$ were omitted, and all high-volatility parameters with an NPV swing of less than $\$ 270,000$ were omitted. The result is a spotlight for the most important parameters to assess and adjust when considering BEB investments. This section will assess these parameters, specify their impact on project economics, discuss temporal and geographical factors impacting these parameters, and recommend ways that these parameters can be made more favorable.

Table 5. Most Influential and Volatile Project Parameters

\begin{tabular}{|c|c|c|}
\hline Parameter & $\begin{array}{c}\text { Influence } \\
\text { (NPV Swing) }\end{array}$ & Volatility Rating \\
\hline Purchase price of BEB & $\$ 3,200,968$ & Medium \\
\hline Purchase price of foregone diesel bus & $\$ 1,731,602$ & Low \\
\hline Grant amount & $\$ 1,500,000$ & Medium \\
\hline Diesel vehicle maintenance & $\$ 1,129,599$ & Medium \\
\hline Annual VMT & $\$ 1,033,894$ & Medium \\
\hline Number of BEBs obtained (depot) ${ }^{\mathrm{a}}$ & $\$ 771,923$ & High \\
\hline BEB vehicle maintenance costs & $\$ 698,440$ & High \\
\hline Charger price (fast) ${ }^{\mathrm{a}}$ & $\$ 495,636$ & High \\
\hline Number of BEBs obtained (fast) ${ }^{\mathrm{a}}$ & $\$ 429,500$ & High \\
\hline Electricity demand charges (fast) ${ }^{\mathrm{a}}$ & $\$ 49,282$ & High \\
\hline
\end{tabular}

a Parameters with parentheses behind them apply specifically to fast- or depot-charge projects. 


\section{Purchase Price of BEBs}

The purchase price of a BEB is the most influential parameter (almost twice as influential as the second-place parameter) and has medium volatility. Fortunately, BEB prices are likely to drop from the current baseline value. This is largely because the price of high-voltage batteries, which are the most expensive components of BEBs, are expected to continue declining (IEA 2019). BEB purchase price could also be significantly lowered by leasing the battery instead of purchasing, as at least a dozen fleets are now doing (Blanca 2019). The purchase price also depends on geographically determined factors such as state and local vehicle taxes, availability and competition of BEB manufacturers, and required power of heating and air conditioning equipment. Agencies can lower prices by placing larger orders and manufacturers can achieve substantial economies of scale. Smaller agencies could join together for a pooled purchase of larger numbers of BEBs to help lower cost. Figure 3 shows the NPV over a wide range of prices, with all other parameters locked at the base case.

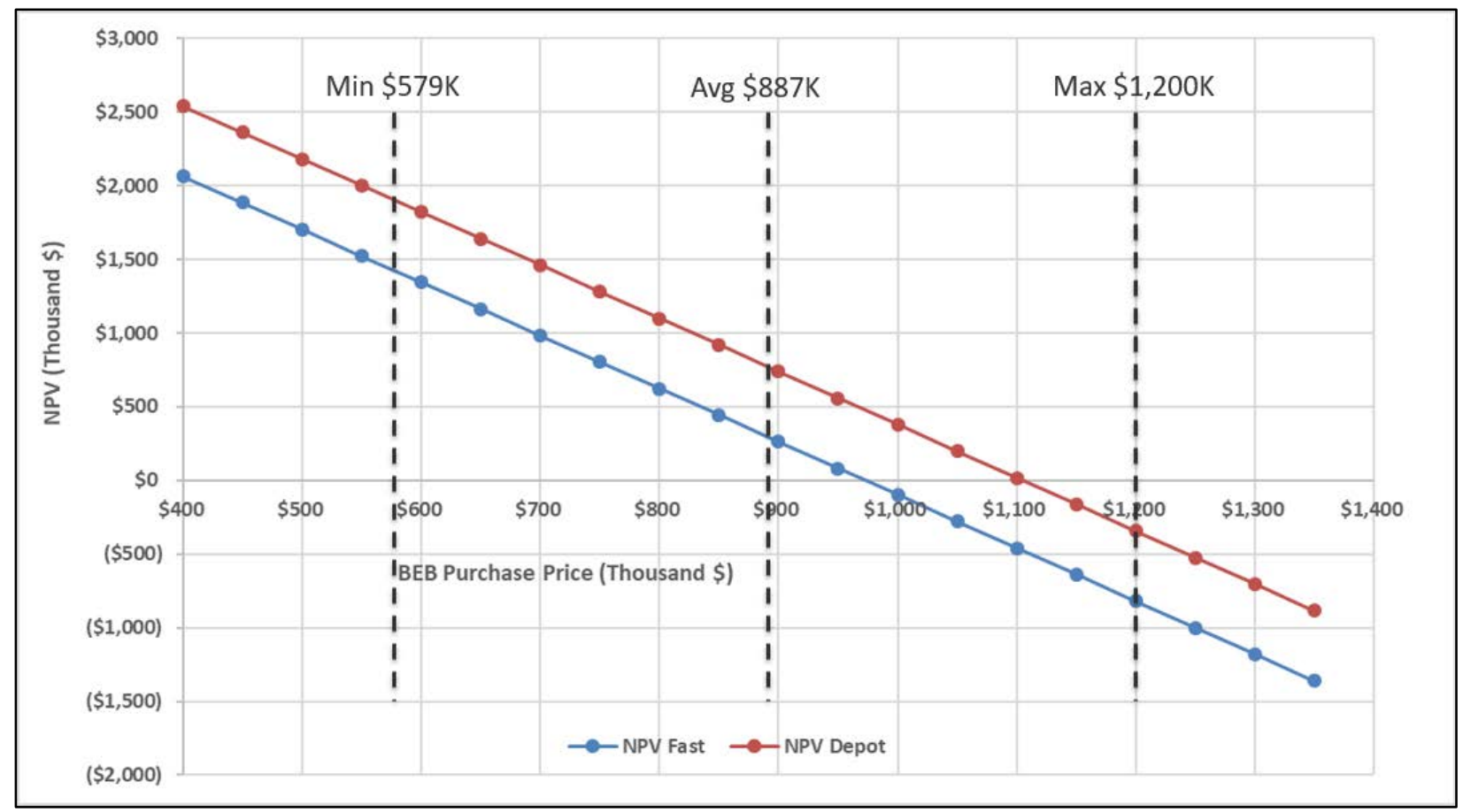

Figure 3. The effect of BEB purchase price on NPV under the fast- and depot-charge scenarios

Figure 3 shows that there is a linear relationship between BEB prices and NPV, with projects being cost-effective [surpassing the required return on investment (ROI) of 3.6\%] for BEBs costing less than $\$ 1.1$ million for the depot-charge scenario and $\$ 970,000$ for the fast-charge scenario. The range of BEB prices paid by fleets in the TRCP report has been from $\$ 579,000$ to $\$ 1.2$ million (TCRP 2018), with an average of $\$ 887,000$. The least expensive BEBs were a batch of 21 BEBs that were converted from IndyGo's existing Gillig buses by Complete Coach Works. These buses were converted in 2014 and have $305-\mathrm{kWh}$ batteries. The $\$ 1.2$ million maximum

BEBs costing less than \$1.1 million for the depot-charge scenario and $\$ 970,000$ for the fast-charge scenario lead to a positive NPV when all other parameters are held at baseline values 
bus cost was from Foothill Transit. These fast-charge buses were procured in 2009 and therefore were prototypes with much higher production costs than current BEBs. The depot-charge scenario is $\$ 477,000$ more cost-effective than the fast-charge scenario regardless of BEB purchase price. This is simple relationship is due to the fact that BEB purchase price does not impact the charger price, number of chargers, demand charges, or any of the other chargerrelated cost components.

\section{Purchase Price of the Foregone Diesel Bus}

The purchase price of the foregone diesel bus is a distant second to the purchase price of a BEB because it is about half as influential and has medium volatility as opposed to high. It does have some factors affecting the price though. One of these is the vehicle taxes of a given state. The components and accessories that are specified in bid documents also impact the price of the diesel bus. BEBs have fewer options that tend to be packaged together, so price increases for the diesel bus do not directly translate to price increases for the BEB. Another factor is local requirements related to air quality, such as the alternative fuel bus mandate by the South Coast Air Quality Management District (2000). This mandate essentially means that the foregone bus is a CNG vehicle with a purchase price that is more expensive than a diesel bus.

A depot-charge project surpasses the required ROI as long as diesel buses are more than $\$ 262,000$, and a fast-charge project surpasses this once the diesel bus costs more than $\$ 395,000$. The minimum realistic price for a diesel bus is $\$ 430,000$, which is in the cost-effective zone for both types of projects. This minimum price came from a Washington State

A depot-charge project surpasses the required ROI as long as foregone diesel buses are more than $\$ 262,000$, and a fast-charge project surpasses this once the diesel bus costs more than $\$ 395,000$ contract price for a large order of buses, as collected and processed by CARB (2016).

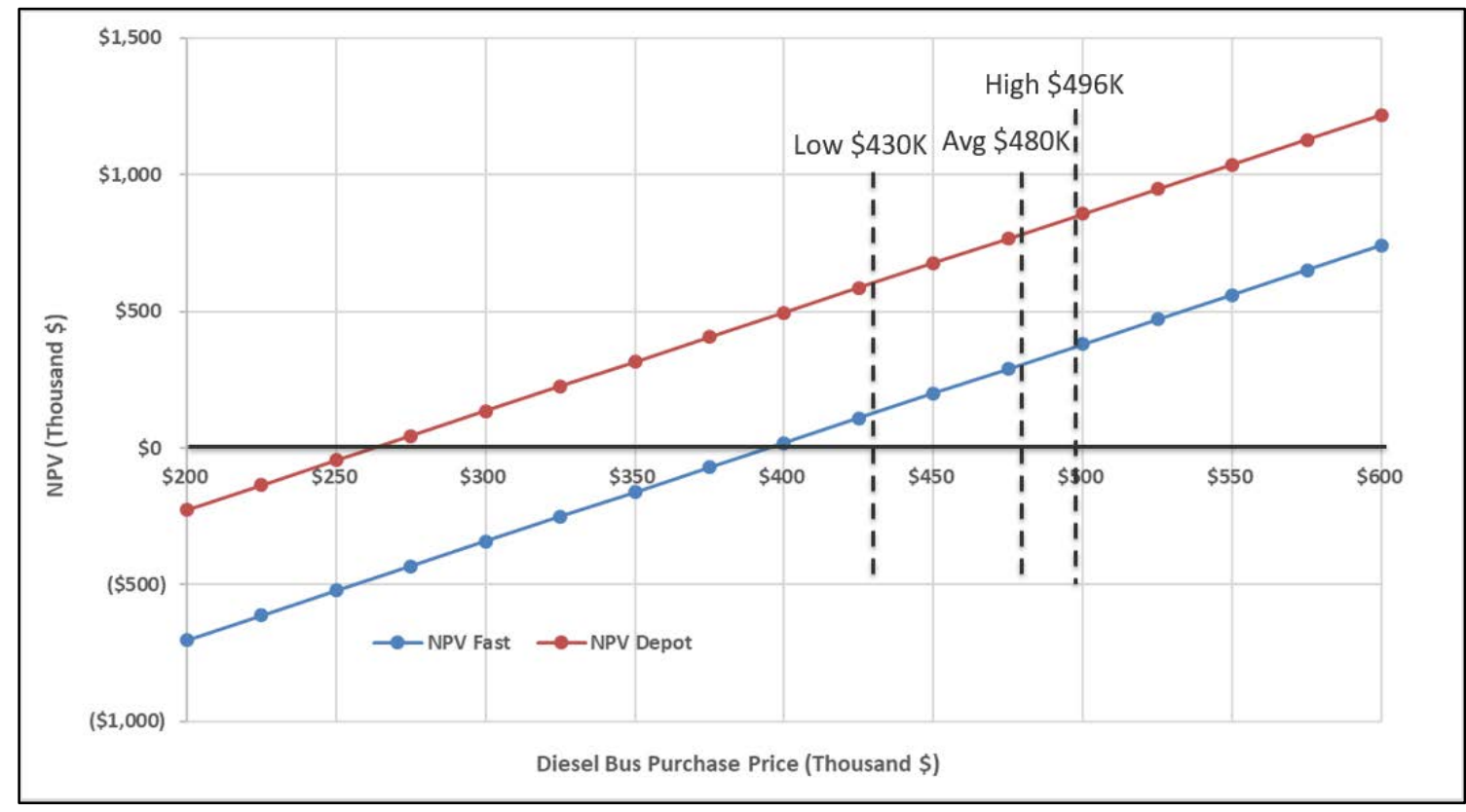

Figure 4. The effect of the foregone diesel bus price on BEB investment 


\section{Grant Amount}

Grants are still an important aspect of BEB projects, as shown by their strong influence on NPV. They counteract part of the BEB purchase, charger purchase, and charger installation so that the cost savings can accrue a positive NPV. Figure 5 shows the impact that a grant has on NPV. A sampling of grant amounts came from the 2018 Low-No program-an $\$ 85$ million grant program run by the FTA that funded 52 projects across the country in 2018 (FTA 2018). The minimum grant awarded under this program was $\$ 403,000$, the maximum was $\$ 2.3$ million, and the average was $\$ 1.5$ million. Depot-charge projects meet the RRR if they can secure a grant of $\$ 715,000$ or more, while fast-charge projects need at least $\$ 1.19$ million to be cost-effective.

Although the Low-No program is the largest BEB grant program to date (with an additional $\$ 85$ million of awarded grants announced in August 2019 [FTA 2019] and another $\$ 130$ million of available funding announced in January 2020 [FTA 2020]), there are

\section{BEB grants and vouchers are available from the Federal Transit Authority, California Air Resources Board, and CALSTART} other similar programs. CARB provides vouchers to help cover the incremental cost of adding zero-emission trucks and buses to fleets in California. The Hybrid and Zero-Emission Truck and Bus Voucher Incentive Program (HVIP) (California HVIP 2019) is managed by CALSTART and provides point-of-sale discounts to purchasers. An agency purchasing a 40-ft BEB can be eligible to receive a $\$ 150,000$ voucher per bus. If the BEB is used in a disadvantaged community, the voucher is $\$ 165,000$. Given state and local goals for BEB adoption, it is likely that there will be more grant programs. Figure 5 can also provide good insight to programs funding buses and charging equipment. It suggests that grants of just over $\$ 715,000$ for depotcharge projects and $\$ 1.19$ million for fast-charge projects could provide enough money to make these projects economically viable for base-case fleets. If targeting the base-case fleets with these grant amounts, the applicants should self-select to ensure projects with better-than-average attributes. 


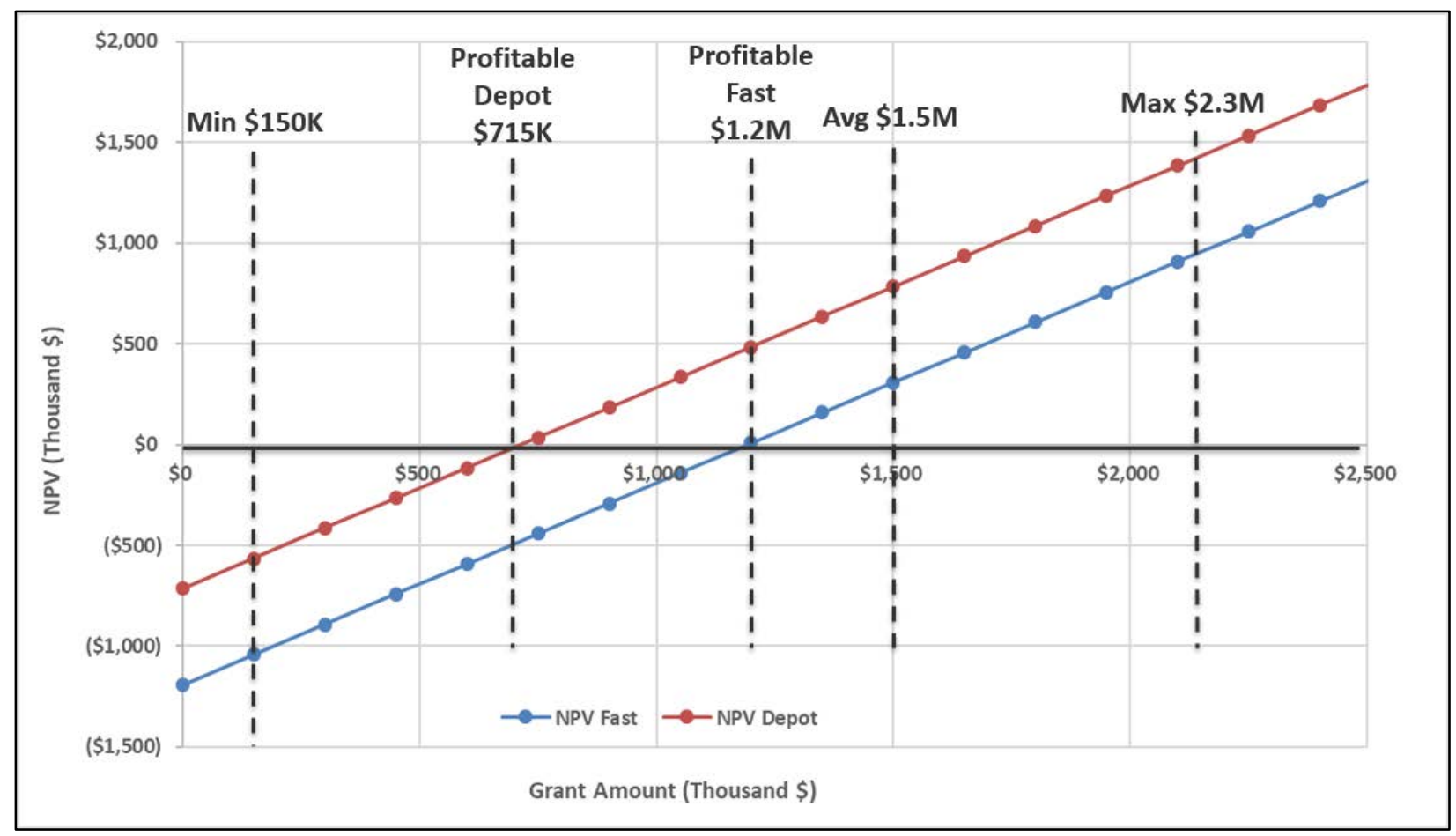

Figure 5. The effect that grant amount has on NPV under the fast- and depot-charge scenarios

\section{Maintenance Costs of Foregone Diesel Buses}

The maintenance costs of diesel buses are the most influential parameter that has medium volatility. This volatility is largely tied to labor costs, which vary across the country based on the local cost of living, unionization, and relative availability/demand for mechanics in the area. It is also tied to garage efficiency, which in turn depends on management practices, equipment owned, and economies of scale. Regulations impacting garage operations and materials disposal can also have an impact.

These are the hypothetical diesel buses that have been replaced by BEBs, so higher maintenance costs lead to better economics for the BEB project that replaces them. Depot-charger projects meet the required ROI as long as the foregone diesel maintenance costs are greater than $\$ 0.27$ per mile.

Depot-charger projects are cost effective as long as the foregone diesel maintenance costs are greater than $\$ 0.27$ per mile. The threshold for fastcharger projects is $\$ 0.64$ per mile The threshold for fast-charger projects is $\$ 0.64$ per mile. Both of these threshold points are less than the average of $\$ 0.88$ per mile, which was reported by fleets in the Utilimarc database (Utilimarc 2019a). The "low" maintenance costs of $\$ 0.37$ per mile is the maintenance cost for the 2-year-old bus grouping in the Utilimarc database. This is the low bookend because it represents the youngest age group in the data set that has settled into a pattern of wear. The depot project returns a positive NPV even at this low cost. The high bookend is at $\$ 1.73$ per mile, which is the average for 12-year-old buses in the Utilimarc data set. Both projects are highly cost-effective at this upper cost, with NPVs of nearly $\$ 1.5$ million and \$2 million for the fast- and depot-charge projects, respectively. 


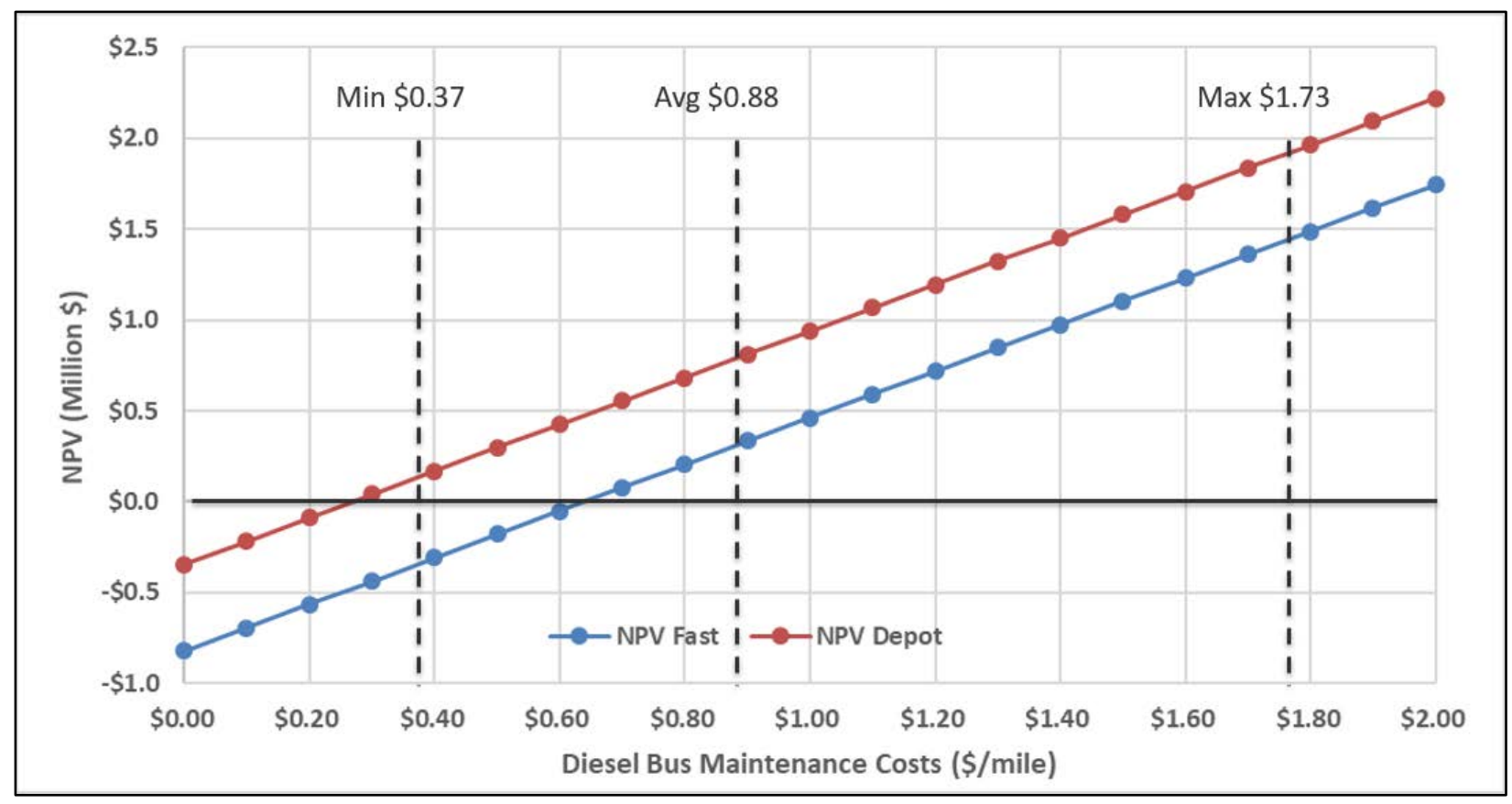

Figure 6. The effect of the maintenance costs of foregone diesel buses on NPV of BEB investment

\section{Annual VMT}

Annual VMT determines how quickly the operational cost savings of a BEB investment accrue over the life of the buses. Therefore, if all other things are held equal, higher VMT results in faster payback periods and higher NPV.

\section{Greater annual VMT means that the per-mile operational savings accrue more quickly and therefore investment payback is achieved more quickly}

Figure 7 shows that the fleets with the lowest average VMT barely meet their RRR on investments in fast-charge projects and comfortably meet it with depot-charge projects.

However, the maximum and minimum VMT listed in Figure 7 are fleet averages. These numbers can vary much greater when one compares individual buses within a fleet. Because higher VMT results in a more cost-effective investment, it is important for fleet managers to place their BEBs in high-mileage routes, as long as these routes can be accommodated by BEB range and adequate charging infrastructure. However, the maximum of 40,000 miles might not be possible with the baseline battery size over a sustained period of time. 


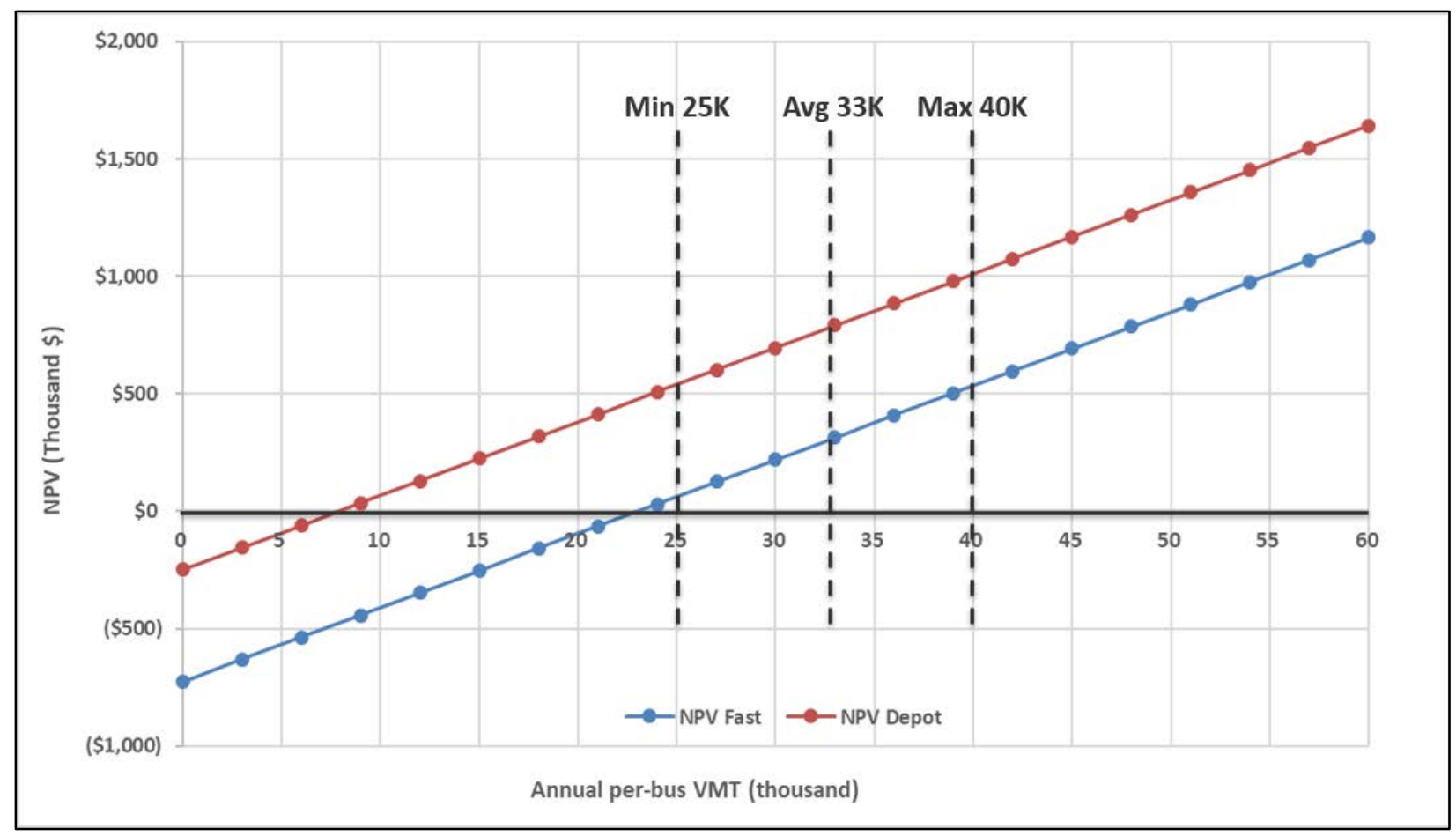

Figure 7. Annual per-bus VMT effect on NPV of BEB investment

The depot- and fast-charge projects have had parallel lines in Figures 3-7 that have not crossed one another. That means that the parameters have not been tied to the choice between the two chargers, and the depot charger has always been the more economical choice. The next section will explore the economic (not logistical) parameters that determine whether depot or fast chargers are a more economical investment for given fleets.

\section{Depot vs. Fast Chargers}

The last five factors in Table 5, along with power draw of chargers, facility electric load delta, utility rate structure, and a handful of other parameters, are related to the choice between a depotcharge or fast-charge project. With baseline inputs (comparing one fast charger per fleet to depot chargers matching the number of buses), fast-charge projects are a substantially less costeffective investment than depot-charge projects due to the additional equipment and demand charge costs. However, fast chargers can be the better investment, depending on fleet conditions. Three of the most important factors to consider are the number of BEBs (as shown in Table 5), power draw of the chargers, and timing of the charges in relation to facility load delta. The dynamics of these three factors are illustrated in Figure 8. 


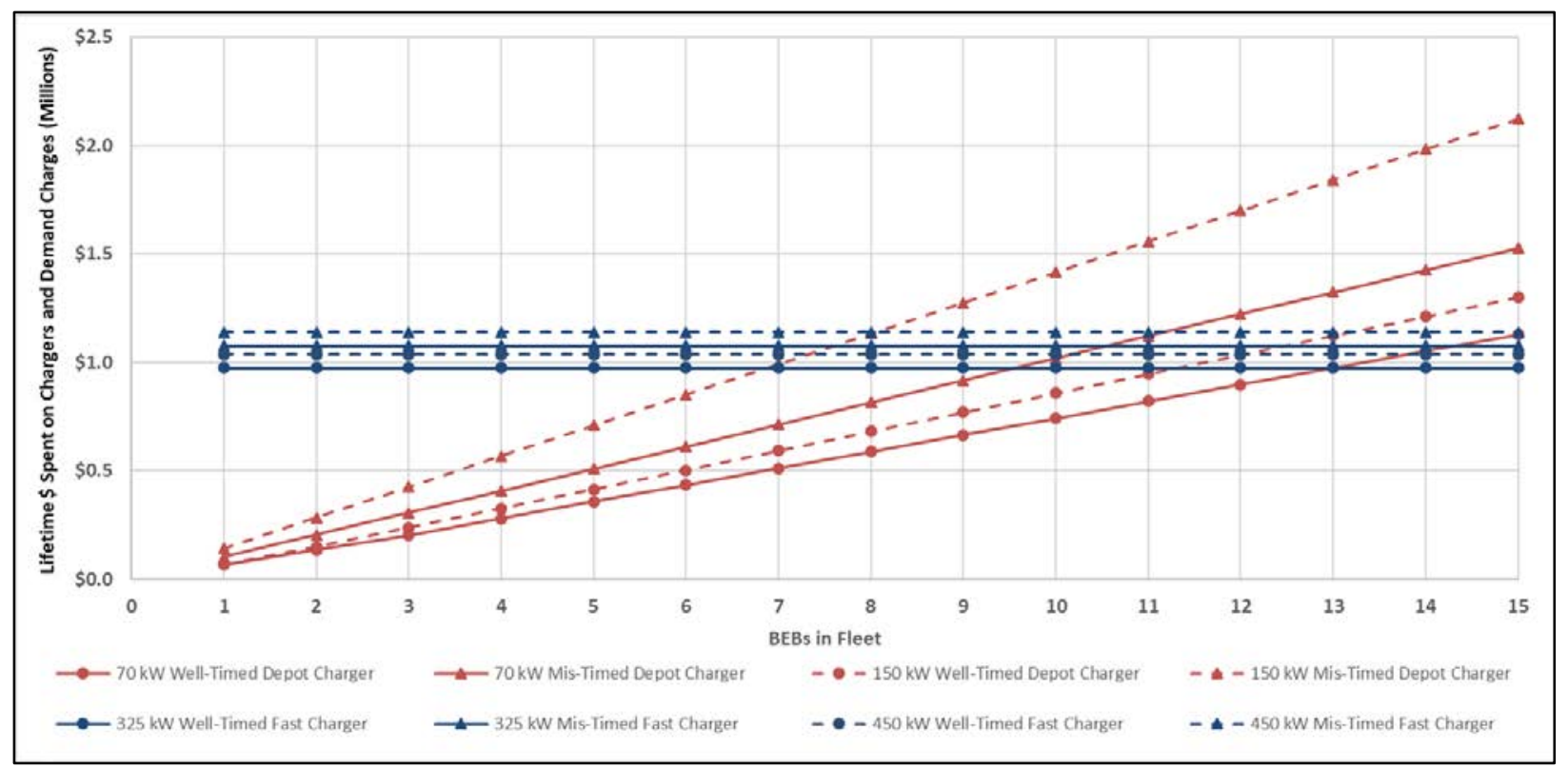

Figure 8. Depot vs. fast charger lifetime costs

Figure 8 is an oversimplification, and this area needs more in-depth research such as was done by Muratori et al. (2019). Only two general scenarios of charge timing are represented: adding the load of all chargers on top of the average load (well-timed) or adding it on top of the peak load (mis-timed). In reality, more can be done to optimally time charging events, including staggering the charging depot chargers and charging when the facility is at minimal load instead of average load. The $70-\mathrm{kW}$ and $325-\mathrm{kW}$ well-timed scenarios are the ones modeled in the baseline scenarios and are not the lowest-load chargers available. However, the $150-\mathrm{kW}$ and $450-\mathrm{kW}$ chargers are the highest load available, so their mis-timed scenarios are the worst case. Purchase price and maintenance is set by charger type (depot vs. fast) regardless of kilowatts. This does not take any cost savings into account for smaller batteries on fast-charge buses because these buses incur costs in order to be compatible with fast charging. Changes in the dollar-per-kilowatt demand charge (which is the second most variable parameter in the model), the bus VMT, or the load delta change these drastically. Furthermore, both depot and fast chargers are assumed to be operating at the same facility. Finally, the assumption that there will be the same number of depot chargers as buses ignores scenarios where multiple buses share a charger at the depot, and assuming that only one fast charger can serve the entire range of buses, while well within the theoretical maximum, would be logistically challenging.

Despite the oversimplification, some lessons can be learned from Figure 8. The likelihood of a fast charger being the more economical way to charge increases with the number of BEBs in a fleet. This is because the costs for fast chargers do not change as long as only one charger is purchased and maintained, and peak load will stay the same because only one bus can charge at a time. Conversely, all depot-charger costs are tied to the number of buses. The base case shows depot chargers becoming more expensive between 7 and 15 buses, depending on which chargers are being compared. The theoretical maximum number of buses to share one fast charger under base-case

Charger power (in $\mathrm{kW}$ ) and charge timing have a greater impact to a fleet using depot chargers than a fleet sharing a fast charger 
conditions is 47 buses if ideally timed, ${ }^{1}$ yet the most buses that currently share one fast charger in real-world operation is 9 buses (by Foothill Transit). ${ }^{2}$ Another lesson from Figure 8 is that charger power (in $\mathrm{kW}$ ) and charge timing have a greater impact to a fleet using depot chargers than a fleet sharing a fast charger. This sensitivity to charger power and charge timing increases with the number of BEBs.

Beyond the parameters mentioned above, the impact that electricity demand charge $(\$ / \mathrm{kW})$, max-average load delta, and equipment cost has on project cost must be considered. To calculate this, the model was rerun three times: once with the demand charge doubled from $\$ 3.45 / \mathrm{kW}$ to $\$ 6.90 / \mathrm{kW}$, once with the maximum-minimum load delta doubled from $203 \mathrm{~kW}$ to $406 \mathrm{~kW}$, and once with upfront charger and installation costs doubled. These scenarios are compared to the base case in Figure 9.

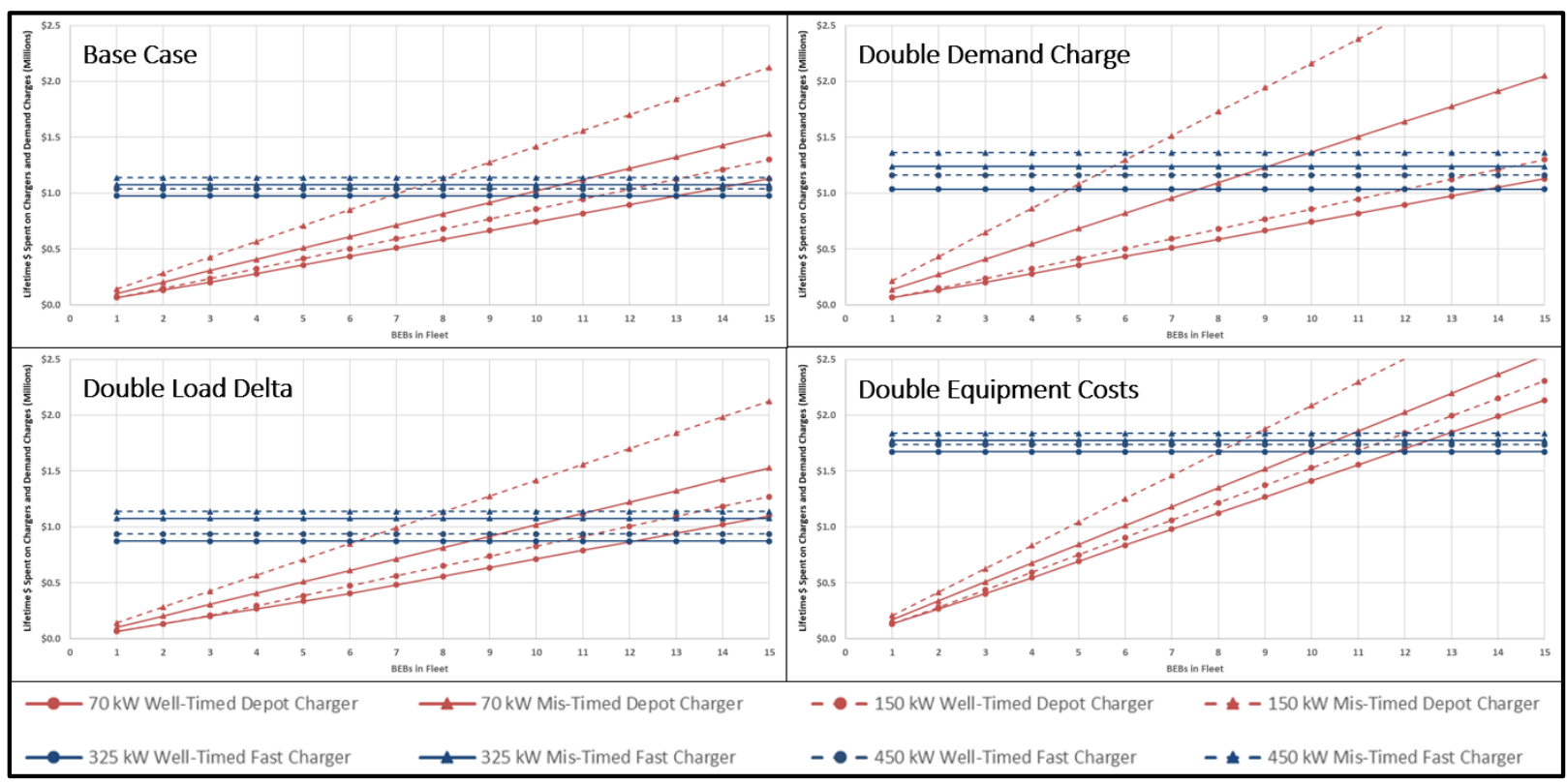

Figure 9. Lifetime costs of chargers with varying demand charges, load delta, and equipment costs

Doubling the demand charge magnifies the differences between the four depot chargers much more than the differences between the fast chargers. Therefore, with high demand charges, fleet managers could save a lot of money by using $70-\mathrm{kW}$ chargers or by timing their charging events well. This doubling has a particularly large impact on the mis-timed $150-\mathrm{kW}$ depot-charger scenario. These chargers have higher lifetime costs than either mis-timed fast-charger scenarios once the fleet has six or more buses. Since demand charge has a much larger range than the other inputs, additional cases must be considered. If the maximum demand charge of $\$ 21.68$ is assumed, the $150 \mathrm{~kW}$ mis-timed depot charger surpasses

Doubling the demand charge magnifies the impact of other choices such as depot vs. fast charger, power of charger, and charge timing

\footnotetext{
${ }^{1}$ Each bus in the base case uses 4,962 kWh per month, and the 325-kW fast charger, if used $24 / 7$, could distribute 237,900 kWh per month.

2 TCRP Report
} 
the lifetime costs of the $325 \mathrm{~kW}$ well-timed fast charger (at $\$ 1.3$ million) with three or more buses. The $70 \mathrm{~kW}$ well-timed depot charger never surpasses this threshold.

Doubling the facility load delta made no difference to the mis-timed charging scenarios because they will still be adding their full load on top of the facility's. Its impact on well-timed charging was also small, reducing the lifetime cost of fast chargers by about $\$ 100,000$. Doubling the load, delta reduced demand charges about $\$ 30,000$ for well-timed charging with more than three buses (using $150-\mathrm{kW}$ chargers) or six buses (using $70-\mathrm{kW}$ chargers).

Doubling equipment and installation costs had a large impact on the lifetime costs of all fast chargers. However, it also had an impact on depot chargers, increasing commensurately with additional chargers. The red lines in Figure 9 are increasing at a steeper rate, placing more importance on the number of BEBs rather than charge timing or power of the depot chargers. The range at which the red lines cross the blue lines condenses from 7-15 buses in the base case to $8-13$ buses in the scenario with doubled equipment costs.

\section{Top Considerations Related to Electric Utility Rate Structure and Load}

Previous sections have shown that various utility rates, charging configurations and equipment have a strong impact on the lifetime cost of charging BEBs and therefore on BEB investment economics. These findings have been based on a simplified model of utility rate structures and economics. However, fleet managers should consider an even larger set of project parameters when deciding whether to invest in BEBs. The larger set, which should be discussed with the fleet's specific utility, includes:

Electricity consumption charges $(\$ / \mathrm{kWh})$, as modeled in previous sections. These can be bundled (electric supply and delivery provided by one entity) or unbundled (electric supply and delivery provided by different entities).

- Seasonal rates. Utilities often have seasonal (summer/winter) variations to their consumption charge rates. Fleets need to make sure these variations are compatible with their usage patterns.

- Time of Use (TOU) rates are often available from the utility that offer less expensive electricity during certain times of day, week, or year. Analysis of compatibility with potential BEB charge schedules should be performed.

- Tiered rates. Some utilities increase or decrease their consumption charges for customers that surpass a monthly consumption threshold. For example, a utility could charge $\$ 0.11 / \mathrm{kWh}$ for the first $25,000 \mathrm{kWh}$ and then $\$ 0.13 / \mathrm{kWh}$ for every $\mathrm{kWh}$ over 25,000 . This rate structure may be used by utilities in place of TOU rates. This should be taken into account when determining how many BEBs to add to the fleet.

Electricity demand charge $(\$ / \mathrm{kW})$, as modeled in previous sections. As with electricity consumption charges, these can have seasonal and TOU components which should be considered. Additionally, fleet managers should consider how demand charges are being 
calculated. For example, demand changes can be calculated based on the highest load throughout the month or only during certain hours.

- Some utilities have "ratchet" clauses that raise the demand charge of low-demand months to a certain percentage of the month with the highest demand. These are particularly impactful if a fleet pilots BEBs for a few months and then has to pay additional ratcheted demand charges for the rest of the year. Fleets wanting to run such a pilot should discuss options such as promotional test rates with their utility in advance.

Other utility bill components. This is a catch-all category that can include late fees, renewable energy or emissions reduction credits and discounts, monthly customer charge, taxes, and discounts. A fleet should ask their utility how these costs and credits could be impacted by the addition of BEBs.

Rate eligibility and alternative rates. Fleet managers should consider if there are alternative rates the site may be eligible for, and/or if the additional load of the BEB will result in the site moving into a different rate class. One example of an alternative rate is an interruptible rate, which allows utilities to cut a customer's power during the utility's peak loads (typically in exchange for lower rates). Special commercial electric vehicle rates are sometimes available, similar to the ones implemented by Pacific Gas and Electric and Southern California Edison (Muller 2019).

Utility-managed charging (or smart charging), which provides a communications interface between the BEB drivers and utility. The drivers or managers enter data on how much battery charge is needed and when, and the utility has the capability to delay the charge within a window that still meets the fleet's needs. Currently there are 38 identified programs in the pilot and demonstration phases (Hanvey 2019). The term "smart charging" can also be used in cases where a fleet operator such as a transit agency can control the timing of the charges through a central control.

Tariffed on-bill financing to pay for charging infrastructure. This rate structure enables the utility to pay the upfront costs of infrastructure and batteries. The fleet pays about what a comparable diesel bus would cost and agrees to a higher monthly electricity bill (in order to pay back the higher upfront costs) that is capped at a level below the estimated fuel savings. This greatly reduces project risk for the fleet, but also reduces their savings on operational costs (Clean Energy Works 2019).

Utility interconnection charges are costs that the utility incurs for the upgrading of equipment to support higher power supply level. These are often passed onto the customer requiring the increased power supply but sometimes paid by the utility if the improvement benefits more customers than just the BEB fleet.

Location of future chargers, and determination if the charger can be located behind the existing meter of the existing facility meter and therefore and aggregate the loads, or if they will be metered separately. Aggregating the loads allows more flexibility for demand charge cost savings through timing controls. 
Delta between monthly peak load and average load, which can be calculated from information provided on most commercial bills. This delta can be entered into the VICE-BEB to focus analysis on a specific fleet location.

Detailed facility load analysis, similar to the one that was done for Valley Transit Authority in Eichman et al. (forthcoming). This, paired with a drive cycle analysis, allows specialists to determine if a set of BEB routes is compatible with the facility load, and what the expected demand charges are.

\section{BEB Range}

BEB range is a parameter directly entered in the financial model, yet it deserves focused consideration. Range is a function of numerous project parameters-BEB battery size, efficiency, duty cycle, auxiliary loads, temperature, driving technique, battery age, and more. These can be

BEB range is a function of numerous project parameters-BEB battery size, efficiency, duty cycle, auxiliary loads, temperature, driving technique, battery age, and more. estimated on a standard drive cycle (as published by Altoona), but these estimates vary greatly from the real-world conditions of some fleets. Some transit agencies have seen their monthly electricity consumption rates more than double during particularly cold months largely due to heating loads (Church 2017), and some have seen consumption rates nearly double during particularly hot months largely due to air conditioning loads (Eudy and Jeffers 2017). To best estimate range, it is recommended that a route profile be performed for a specific agency. Such a profile includes geotracking specific buses and compiling a representative duty cycle. A route profile should also take temperature into account because electrically driven air conditioners and heating can lower the overall efficiency significantly.

BEB range impacts a number of project parameters that can have a significant impact on project economics. Foremost, range impacts the number and location of chargers. BEBs with short range generally require on-route fast chargers, and the number of chargers generally has to increase as range decreases. Sometimes range limitations may require the purchase of additional buses to allow recharge time while servicing the same number of passengers. A route profile can determine real expected range for a specific fleet and help minimize costs.

\section{Conclusion}

Investments in BEBs and associated charging infrastructure can be cost-effective in many cases, and an average fleet (our base case in this study) achieves an NPV of $\$ 785,000$ and discounted payback of 3.6 years on such an investment.

However, there are many project parameters that make or break such an investment, and some are much more important to assess than others. The most important parameters were determined by looking at how influential they are on the project NPV and how volatile they are across time and location. The most important parameters for fleet managers or grant administrators to assess when determining the likely profitability of a BEB investment are as follows:

1. BEB purchase price. Potential BEB investors should first make sure that they can procure $\mathrm{BEBs}$ at a reasonable price. This depends on time (as BEB prices are generally dropping), 
geography (where more reasonable prices can be found), selected options (such as ....), and negotiating a good contract price (where bulk orders can reduce prices).

2. Purchase price of foregone diesel bus. If a fleet faces unusually expensive diesel bus prices, they are particularly well suited for a BEB investment.

3. Grant amount. At this early stage of market development, a grant is needed to make most BEB investments cost-effective. Fleets should seek the largest grant possible. Grant administrators, however, could likely seed the highest number of BEB projects if their grants were about $\$ 715,000$ for depot-charge projects and $\$ 1.2$ million for fast-charge projects.

4. Maintenance costs of foregone diesel vehicles. If a fleet faces high maintenance costs (over $\$ 0.88$ per mile) on their diesel vehicles, the switch to BEBs becomes even more cost-effective. Fleets facing such high costs might be located in areas with high labor costs or might not have equipment or economies of scale that bring the maintenance costs down.

5. Annual VMT. Large BEB investments are paid back by operations savings mile by mile. Therefore, fleets should put their new BEBs on their highest mileage routes. Some fleets (such as those in suburban areas) have more high-mileage routes than others, so these fleets are more likely to have cost-effective investments in BEBs.

6. Choice of depot or fast charger. Depot chargers are generally more economical over the BEB life if a fleet has less than 13 BEBs, their charging can be timed to avoid peak electrical draw, and all other parameters are base case. However, the economics of fast chargers become more favorable with more BEBs, more powerful $(>70 \mathrm{~kW})$ depot chargers, increased dollar-per-kilowatt demand charge, larger facility electrical load delta, or increased charging equipment costs. Particular focus must be paid to the demand charge, as it is one of the most variable parameters.

7. BEB range for a particular fleet can be determined through a route profile. A route profile helps determine the range of a BEB in route-specific applications and therefore helps transit agencies optimize their number of buses and chargers, which will then minimize project costs.

8. Accuracy of economic analysis can be greatly improved by collecting fleet-specific inputs and modeling a specific fleet. This analysis has modeled average and common inputs, but outputs can be much more accurate and actionable if a fleet decision maker downloads the VICE-BEB at www.afdc.energy.gov and model their specific fleet.

By focusing on these project parameters, fleet managers can maximize the cost-effectiveness of a BEB investment. Fleet managers can download the VICE-BEB model from the AFDC website to move from the generalizations in this report to findings better tailored to their specific fleet. However, even the VICE-BEB model has shortcomings that can only be remedied by further research. Foremost, additional research into the average, maximum, and minimum values for each of the fleet parameters is needed, especially at this dynamic stage in market development. The TCRP report did a great job collecting these data in a nascent market, but they will be made 
much more robust as the market develops. The impact that temperature, auxiliary loads, and driving style have on BEB efficiency needs deeper research. The complex relationship between charge timing, facility electrical load, and demand charges needs much more research as well. The economics of battery leasing need to be explored as prices and other inputs become better established. Such investigations should be done both broadly at research institutes and at a fleetlevel with consultations involving both the utility and fleet. In addition, the value of and potential markets for batteries in stationary applications after the end of their transportation life needs to be analyzed.

\section{References}

10 CFR Part 490. 1996. Alternative Fuel Transportation Program. Accessed 9/6/2019 at https://www.govinfo.gov/app/details/CFR-2011-title10-vol3/CFR-2011-title10-vol3-part490

AFDC. 2018. "Maps and Data - Average Annual Fuel Use by Vehicle Type," Alternative Fuels Data Center, U.S. Department of Energy, accessed September 2, 2019, https://afdc.energy.gov/data/10308.

AFDC. 2019. "State Laws and Incentives," Alternative Fuels Data Center, U.S. Department of Energy, accessed September 2, 2019, https://afdc.energy.gov/laws/state.

AFLEET. 2018. “Alternative Fuel Life-Cycle Environmental and Economic Transportation (AFLEET) Tool,” Argonne National Laboratory, accessed September 2, 2019, https://greet.es.anl.gov/afleet.

APTA. 2013. "Standard Bus Procurement Request for Proposal (RFP)," American Public Transportation Association (APTA), published May 23, 2013, https://www.apta.com/researchtechnical-resources/standards/procurement/apta-bts-bpg-gl-001-13/.

APTA. 2018. Public Transportation Fact Book. Accessed July 23, 2019 at https://www.apta.com/resources/statistics/Documents/FactBook/2018-APTA-Fact-Book.pdf

Blanco, Sebastian. April 18, 2019. "Proterra Ready For Electric Bus Battery Leasing With \$200Million Credit Facility. Forbes. www.forbes.com/sites/sebastianblanco/2019/04/18/proterraready-for-electric-bus-battery-leasing-with-200-million-credit-facility/\#3b81b5b52314

BLS. May 2017. “Occupational Employment and Wages: Bus Drivers, Transit and Intercity.”

California HVIP. 2019. Accessed September 4, 2019, https://www.californiahvip.org/.

CARB. 2016b "Advanced Clean Transit - Cost Assumptions and Data Sources," CARB, updated October 3, 2016, https://arb.ca.gov/msprog/bus/tco assumptions.xlsx.

CARB. 2016a. "Draft CARB Transit Fleet Cost Model," accessed September 2, 2019, https://ww3.arb.ca.gov/msprog/ict/meeting/mt170626/170626transitfleetcostmodel.xlsx. 
Church, Jonathan E. "Worcester Regional Transit Authority. WRTA/Mass Dot, September 28, 2017, "Battery Electric Bus Deployment Project,"

http://www.umasstransportationcenter.org/Document.asp?DocID=319.

Clean Energy Works. 2019. Tariffed On-Bill Finance to Accelerate Clean Transit. Accessed January 2, 2020 at www.cleanenergyworks.org/clean-transit/

Eichman, Josh; Andrew Kotz; Eric Miller; and Ken Kelly (forthcoming). Valley Transit Authority Fleet Electrification and Grid Impacts Assessment. NREL Technical Report.

EIA 2019a. "Weekly Retail Gasoline and Diesel Prices," Petroleum \& Other Liquids, U.S. Energy Information Administration, accessed September 2, 2019, https://www.eia.gov/dnav/pet/pet_pri_gnd_dcus_nus_a.htm.

EIA. 2019b. Annual Energy Outlook 2019, U.S. Energy Information Administration, released January 24, 2019, https://www.eia.gov/outlooks/aeo/index.php.

Eudy, Leslie and Matthew Jeffers, Foothill Transit Battery Electric Bus Demonstration Results: Second Report, National Renewable Energy Laboratory, NREL/TP-5400-67698. June 2017, https://www.nrel.gov/docs/fy17osti/67698.pdf.

Eudy, Leslie and Matthew Jeffers, Zero-Emission Bus Evaluation Results: County Connection Battery Electric Buses, National Renewable Energy Laboratory, December 2018, www.nrel.gov/docs/fy19osti/72864.pdf.

FTA. 2018. "Fiscal Year 2018 Low or No-Emission (Low-No) Bus Program Projects," U.S. Department of Transportation, announced August 24, 2018, https://www.transit.dot.gov/funding/grants/fiscal-year-2018-low-or-no-emission-low-no-busprogram-projects.

FTA. 2019. "U.S. Department of Transportation Announces $\$ 85$ Million in Grants for Projects Nationwide to Expand Advanced Bus Technologies," FTA, U.S. Department of Transportation, July 26, 2019, www.transit.dot.gov/about/news/us-department-transportation-announces-85million-grants-projects-nationwide-expand.

FTA. 2020. Low or No Emission Program (Low-No Program) - FY2020 Notice of Funding. January 17, 2020. www.transit.dot.gov/funding/applying/notices-funding/low-or-no-emissionprogram-low-no-program-fy2020-notice-funding

Gaines, Linda, Anant Vyas, and John L. Anderson. "Estimation of fuel use by idling commercial trucks." Transportation research record 1983, no. 1 (2006): 91-98.

Hardman S, Chandan A, Tal G and Turrentine T 2017 The effectiveness of financial purchase incentives for battery electric vehicles-a review of the evidence Renew. Sustain. Energy Rev. 80 $1100-11$

Hensher, David A. Bus transport: Economics, policy and planning. Vol. 18. Elsevier, 2007. 
Howell, David, Brian Cunningham, and Tien Duong, "Overview of the DOE VTO Advanced Battery R\&D Program,” U.S. Department of Energy, June 6, 2016, https://www.energy.gov/sites/prod/files/2016/06/f32/es000_howell_2016_o_web.pdf.

ICCT. 2019. "The Surge of Electric Vehicles in United States Cities," June 2019, https://theicct.org/sites/default/files/publications/ICCT_EV_surge_US_cities_20190610.pdf

IEA (2019), "Global EV Outlook 2019", IEA, Paris, www.iea.org/publications/reports/globalevoutlook2019/.

Levy, Alan. January 17, 2019. "The Verdict's Still Out on Battery-Electric Buses," Citylab. Accessed 9/6/2019 at https://www.citylab.com/transportation/2019/01/electric-bus-batteryrecharge-new-flyer-byd-proterra-beb/577954/

Mass Transit. 2015. "BYD Announces 12 year Battery Warranty". www.masstransitmag.com/home/press-release/12058920/byd-motors-llc-byd-announces-12year-battery-warranty

Matteo Muratori, Emma Elgqvist, Dylan Cutler, Joshua Eichman, Shawn Salisbury, Zachary Fuller, and John Smart, "Technology Solutions to Mitigate Electricity Cost for Electric Vehicle DC Fast Charging," Applied Energy 242 (May 15, 2019): 415-23, https://www.sciencedirect.com/science/article/pii/S0306261919304581.

McLaren, Joyce. 2017. A Survey of U.S. Demand Charges. Clean Energy Group Webinar. Accessed December 23, 2019 at www.nrel.gov/solar/assets/pdfs/2017-us-demand-chargeswebinar.pdf

Muller, Miles. 2019. Reforming Rates for Electric Trucks, Buses \& Fast Chargers. Natural Resources Defense Council. Accessed December 23, 2019 at www.nrdc.org/experts/milesmuller/reforming-rates-electric-trucks-buses-fast-chargers-0

MTA. 2014. "MTA to Purchase 120 New Buses," MTA, September 19, 2014, http://www.mta.info/press-release/nyc-transit/mta-purchase-120-new-buses.

National Association of Convenience Stores, State of the Industry Report of 2018 Data, accessed September 3, 2019, www.convenience.org/Solutions/Store/Products/NACS-State-of-theIndustry-Report-of-2018-Data-wit.

New Flyer. 2019. "Xcelsior Charge: How it works". Accessed 9/6/19 at https://www.newflyer.com/site-content/uploads/2017/10/Xcelsior-CHARGE-HowItWorksCHargingSolutions.pdf.

Nykvist, Björn, and Måns Nilsson, "Rapidly Falling Costs of Battery Packs for Electric Vehicles," Nature Climate Change 5 (2015): 329-32, https://www.nature.com/articles/nclimate2564. 
O’Keefe, M.P., Simpson, A., Kelly, K.J., and Pederson, D.S., "Duty Cycle Characterization and Evaluation Towards Heavy Hybrid Vehicle Applications," SAE Paper No. 2007-01-0302, 2007, doi:10.4271/2007-01-0302

Pennsylvania Transportation Institute. 2004. Sturaa Test 12 Year 500,000 Mile Bus from Gillig Corporation Model Low floor. Report Number: PTI-BT-R0410. Penn State.

Pennsylvania Transportation Institute. 2007. Sturaa Test 12 Year 500,000 Mile bus from New Flyer. Report Number: PTI-BT-R0704. Penn State.

Pennsylvania Transportation Institute. 2014. Federal Transit Bus Test for BYD Electric Bus. Report Number: LTI-BT-R1307. Penn State.

Pennsylvania Transportation Institute. 2017. Federal Transit Bus Test for Proterra Catalyst E2. Report Number: LTI-BT-R1706-P. Penn State.

Pennsylvania Transportation Institute. 2018. Federal Transit Bus Test for Nova L920 LFSe Battery-Electric Bus. Report Number: LTI-BT-R1703. Penn State.

Proterra. 2019a. "Simplified Parts Support". Accessed 9/5/2019 at https://www.proterra.com/customer-support/parts/

Proterra. 2019b. Standard Limited Warranty Battery System. Accessed 9/5/2019 at https://www.proterra.com/wp-content/uploads/2018/05/PROTERRA-40-FT-SPECS_4.30.18$\underline{1 . p d f}$.

S\&P Global. 2019. "S\&P Municipal Bond Index,” accessed September 2, 2019, https://us.spindices.com/indices/fixed-income/sp-municipal-bond-index.

South Coast AQMD. 2000. "Rule 1192 - Clean On-Road Transit Buses,", accessed September 4, 2019, http://www.aqmd.gov/home/rules-compliance/rules/fleet-rules/transit-buses.

Hanvey, Conor. 2019. EV Managed Charging: Lessons from Utility Pilot Programs. Smart Electric Power Alliance. Accessed January 2, 2020 at https://sepapower.org/knowledge/evmanaged-charging-lessons-from-utility-pilot-programs/

Tong, Fan, Chris Hendrickson, Allen Biehler, Paulina Jaramillo, and Stephanie Seki. "Life cycle ownership cost and environmental externality of alternative fuel options for transit buses." Transportation Research Part D: Transport and Environment 57 (2017): 287-302.

Traffic21 Institute. January 2017. "Which Alternative Fuel Technology is Best for Transit Buses?” Carnegie Mellon University. https://www.cmu.edu/energy/education-outreach/publicoutreach/17-104\%20Policy\%20Brief\%20Buses_WEB.pdf

Utilimarc. 2019a. "Compare Your Fleet to Your Peers with Benchmarking," Utilimarc, accessed September 2, 2019, https://utilimarc.com/fleet-management-products/benchmarking/. 
URDB. 2019. "Electric Utility Rates,", OpenEI, accessed September 3, 2019, https://openei.org/wiki/Utility_Rate_Database.

Yang Z, Slowik P, Lutsey N and Searle S 2016 Principles for Effective Electric Vehicle Incentive Design (Washington, DC: 


\section{Appendix: Calculated Parameters}

Table A-1. Calculated Parameters

\begin{tabular}{|c|c|c|}
\hline Parameter & Unit & Calculation \\
\hline Annual diesel use & $\begin{array}{l}\text { Gallons per } \\
\text { year }\end{array}$ & = Num_Vehicles*Annual_Km*(Diesel_Efficiency/100) \\
\hline $\begin{array}{l}\text { Incremental cost } \\
\text { of all vehicles } \\
\text { (BEBs more than } \\
\text { diesel buses) }\end{array}$ & $\$ /$ vehicle & $\begin{array}{l}\text { = (Cost_Electric_Bus+Battery_Cost+Addl_Shipping_Costs) - } \\
\text { Cost_Diesel_Bus }\end{array}$ \\
\hline $\begin{array}{l}\text { Annual electricity } \\
\text { use }\end{array}$ & kWh/year & $\begin{array}{l}=(\text { Num_Vehicles*Annual_Mi*[EV_Efficiency/100])+([1- } \\
\text { Charger_Efficiency }]^{*}[\text { Num_Vehicles*Annual_mi* }\{\text { EV_efficiency } / 1 \\
\text { 00\}]) }\end{array}$ \\
\hline $\begin{array}{l}\text { Monthly } \\
\text { electricity use }\end{array}$ & $\mathrm{kWh} / \mathrm{month}$ & $\begin{array}{l}=([\text { Num_Vehicles*Annual_mi*EV_Efficiency]/[100*12] })+([1- \\
\text { EVSE_Efficiency }]^{*}\left[\left\{\text { Num_Vehicles }{ }^{*} \text { Annual_Mi*EV_Efficiency }\right\} /\{10\right. \\
\left.\left.\left.0^{*} 12\right\}\right]\right)\end{array}$ \\
\hline Battery range & $\begin{array}{l}\text { Miles per } \\
\text { charge }\end{array}$ & = Battery_Capacity*100/EV_Efficiency \\
\hline $\begin{array}{l}\text { Distance driven } \\
\text { per day }\end{array}$ & Miles per day & = Annual_Km/Days_Per_Year \\
\hline Charges per day & $\begin{array}{l}\text { Full charges } \\
\text { per day }\end{array}$ & = Daily_Distance/Battery_Range \\
\hline $\begin{array}{l}\text { Battery } \\
\text { replacement cost }\end{array}$ & Dollars & = Battery_Cost-(Battery_Cost*Battery_Cost_Redux*Battery_Life) \\
\hline $\begin{array}{l}\text { Monthly demand } \\
\text { charge }\end{array}$ & Dollars & = kW_Demand_Charge*(Peak_Draw-Monthly_Load_Delta) \\
\hline Peak draw & $\mathrm{kW}$ & = Number_of_Chargers*Peak_Draw_Per_Charger \\
\hline $\begin{array}{l}\text { Monthly load } \\
\text { delta }\end{array}$ & kW & = Num_Diesel_Buses_at_Facility*Load_Delta_Per_Bus \\
\hline
\end{tabular}

